\title{
Review
}

\section{Beyond lipid-lowering: effects of statins on cardiovascular and cerebrovascular diseases and cancer}

\author{
Yoichi Morofuji ${ }^{1,}{ }^{*}$, Shinsuke Nakagawa ${ }^{2}$, Kenta Ujifuku ${ }^{3}$, Takashi Fujimoto ${ }^{4}$, Kaishi Otsuka ${ }^{5}$, Masami Niwa $^{6}$ and \\ Keisuke Tsutsumi ${ }^{1}$ \\ 1 Department of Neurosurgery, National Hospital Organization Nagasaki Medical Center, 2-1001-1 Kubara, \\ Omura, Nagasaki 856-8562, Japan; morofujiyoichi@gmail.com (Y.M.), tsutsumi.keisuke.pn@mail.hosp.go.jp \\ (K.T.) \\ 2 Department of Pharmaceutical Care and Health Sciences, Faculty of Pharmaceutical Sciences, Fukuoka \\ University, 8-19-1 Nanakuma, Jonan-ku, Fukuoka 814-0180, Japan; shin3@fukuoka-u.ac.jp (S.N.) \\ 3 Department of Neurosurgery, Graduate School of Biomedical Sciences, Nagasaki University, 1-7-1 Sa- \\ kamoto, Nagasaki 852-8501, Japan; kentaujifuku@hotmail.com (K.U.) \\ 4 Division of Gerontology and Geriatric Medicine, Department of Medicine, University of Washington School \\ of Medicine, Seattle, WA 98108, USA; t.fujimototakashi@gmail.com (T.K.) \\ 5 Department of Cardiology, National Hospital Organization Nagasaki Medical Center, 2-1001-1 Kubara, \\ Omura, Nagasaki 856-8562, Japan; kai51005100@gmail.com (K.O.) \\ 6 BBB Laboratory, PharmaCo-Cell Company Ltd., Dai-ichi-senshu bldg. 2nd Floor, 6-19 Chitose-machi, Naga- \\ saki 852-8135, Japan; niwa@pharmacocell.co.jp (M.N.) \\ * Correspondence: morofujiyoichi@gmail.com; Tel.: +81-957-52-3121
}

\begin{abstract}
The 3-hydroxy-3-methylglutaryl-coenzyme A (HMG-CoA) reductase inhibitors, also known as statins, are administered as first-line therapy for hypercholesterolemia, both as primary and secondary prevention. Besides the lipid-lowering effect, statins have been suggested to inhibit the development of cardiovascular disease through anti-inflammatory, antioxidant, vascular endothelial function-improving, plaque-stabilizing, and platelet aggregation-inhibiting effects. The preventive effect of statins on atherothrombotic stroke has been well established, but statins can influence other cerebrovascular diseases. This suggests that statins have many neuroprotective effects in addition to lowering cholesterol. Furthermore, research suggests that statins cause pro-apoptotic, growth-inhibitory, and pro-differentiation effects in various malignancies. Preclinical and clinical evidence suggests that statins inhibit tumor growth and induce apoptosis in specific cancer cell types. The pleiotropic effects of statins on cardiovascular and cerebrovascular diseases have been well established; however, the effects of statins on cancer patients have not been fully elucidated and are still controversial. This review discusses the recent evidence on the effects of statins on cardiovascular and cerebrovascular diseases and cancer. Additionally, this study describes the pharmacological action of statins, focusing on the aspect of 'beyond lipid-lowering.'
\end{abstract}

Keywords: cancer, cerebrovascular diseases, cardiovascular diseases, pleiotropic effect, statin

\section{Introduction}

Statins potently inhibit 3-hydroxy-3-methylglutaryl-coenzyme A (HMG-CoA) reductase by competitively blocking the active site of the enzyme. Statins decrease cholesterol biosynthesis and thereby reduce plasma cholesterol levels. The development of statins as cholesterol-lowering agents began in the mid-1970s when they were discovered as a fungal metabolite, with the first of these being a natural product called mevastatin [1]. Since this discovery, vigorous efforts have been made to develop novel statins, leading to the introduction of a total of eight varieties to date. Over four decades of use, statins have become one of the most widely prescribed drugs globally, especially for cardiovascular diseases [2-8]. The association between dyslipidemia and cardiovascular disease has been comprehensively established. On the other hand, statins exhibit pleiotropic properties that are independent of their lipid-lowering effects[9]. Independent of lipid-lowering effect, statins have been suggested to inhibit the development of cardiovascular disease through anti-inflammatory, antioxidant, vascular endothelial function-improving, plaque- 
stabilizing, and platelet aggregation-inhibiting effects [10-12]. The preventive effect of statins on atherothrombotic stroke is well established, but statins can influence other cerebrovascular diseases. Thus, statins have many neuroprotective effects in addition to lowering cholesterol. Furthermore, research suggests that statins cause pro-apoptotic, growth-inhibitory, and pro-differentiation effects in various malignancies [13]. Preclinical and clinical evidence suggests that statins inhibit tumor growth and induce apoptosis in specific cancer cell types. The pleiotropic effects of statins on cardiovascular and cerebrovascular diseases have been well established; however, the effects of statins on cancer patients have not yet been fully elucidated and are still controversial. This review discusses the recent evidence on the effects of statins on cardiovascular and cerebrovascular diseases and cancer, in addition to the pharmacological action of statins, focusing on the aspect of 'beyond lipid-lowering.'

\section{Pharmacological action of statins}

Cholesterol is an essential component to maintain life, serving as a basic ingredient for cell membranes, steroid hormones, and bile acids. It is categorized into exogenous cholesterol, which is ingested via food, and endogenous cholesterol, which is primarily synthesized in the liver, with the latter being predominant in the human body. The cholesterol biosynthesis pathway involves multistage reactions, where the rate-determining step is the reaction to synthesize mevalonate from HMG-CoA. This rate-determining step is catalyzed by HMG-CoA reductase, which expression is subject to feedback control by intracellular cholesterol content. The homeostasis of intracellular cholesterol is maintained through this feedback control [14]. Statins are indispensable components for the treatment of dyslipidemia and the prevention of cardiovascular diseases due to their ability to suppress cholesterol biosynthesis by inhibiting HMG-CoA reductase.

The first statin, compactin (mevastatin), was discovered by Endo et al. in 1973 within the culture medium of Penicillium citrinum [15]. Since this discovery, vigorous efforts have been made to develop novel statins, leading to the introduction of eight statin varieties to date. Although these statins commonly possess a structure similar to HMG-CoA, their cholesterol-lowering effect and pharmacokinetics differ [1]. Clinically employed statins include lipophilic simvastatin, atorvastatin, pitavastatin, and fluvastatin and hydrophilic pravastatin and rosuvastatin. While lipophilic statins are absorbed into cells via passive diffusion, hydrophilic statins require organic anion transport proteins (OATPs) to become absorbed into the liver. Except for fluvastatin, statins serve as substrates for OATP1B1, which gene polymorphism is reportedly responsible for the varying pharmacokinetics of statins [16]. Cytochrome P450 (CYP) is involved in the metabolism of some statins, with simvastatin and atorvastatin primarily being metabolized by CYP3A4 and fluvastatin being metabolized by CYP2C9. However, other statins are scarcely metabolized by CYP [17]. Generally, statins are well-tolerable and seldomly cause serious adverse events. However, one noteworthy adverse reaction is myopathy, which may progress to fatal rhabdomyolysis [18]. Therefore, when high statins doses are administered for treatment or when used concomitantly with drugs that inhibit CYPs or OATPs, caution should be exercised to avoid increased risks for adverse reactions.

The cholesterol-lowering effect of statins is primarily attributed to a compensatory increase in the expression of low-density lipoprotein (LDL) receptor due to the suppressed endogenous cholesterol synthesis rather than a decrease in intracellular cholesterol biosynthesis. The increased LDL receptor level, in turn, promotes hepatic uptake of blood LDL-cholesterol (LDL-C), thereby reducing its blood concentrations. This regulation of the LDL receptor expression by intracellular cholesterol content is mediated by a transcriptional regulatory mechanism comprising sterol regulatory element (SRE) and one of its binding proteins, SRE-binding protein 2 (SREBP-2) $[19,20]$. sterol regulatory elementbinding protein (SREBP)-2 forms a dimer with SREBP cleavage-activating protein (SCAP), which is a cholesterol sensor, on the endoplasmic reticulum membrane. Under 
cholesterol-rich conditions, the SREBP-SCAP complex forms a trimer with an insulin-inducing gene (INSIG) and remains on the endoplasmic reticulum membrane. Conversely, when intracellular cholesterol content decreases, the SREBP-SCAP complex detaches from INSIG and migrates to the Golgi apparatus. Subsequently, the N-terminus of SREBP-2 is cleaved by proteases (S1P and S2P) in the vicinity of the membrane-binding site [21]. The cleaved SREBP migrates into the nucleus and binds to SRE as a transcriptional factor, thereby promoting the transcription of various genes, including those of the LDL receptor and HMG-CoA reductase (Figure 1)

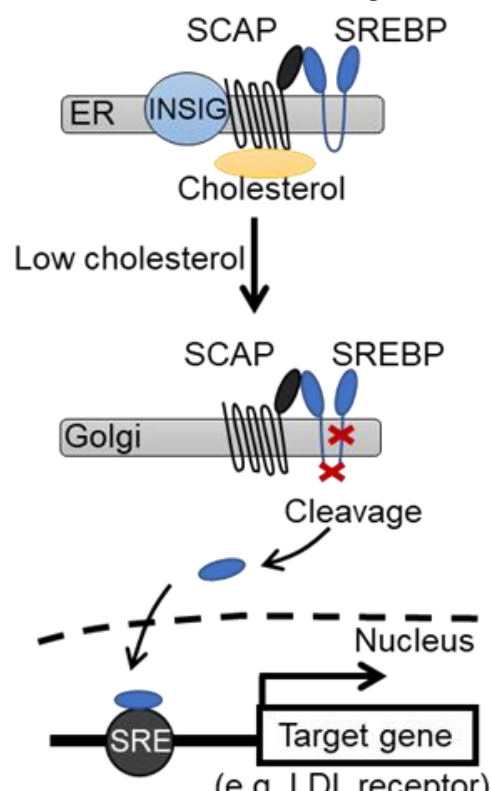

Figure 1. Genetic effects of cholesterol on sterol synthesis and low-density lipoprotein (LDL) receptor expression

In the presence of cholesterol, which regulates the expression of the SREBP activation pathway and the LDL receptor gene, the SREBP-SCAP complex binds to INSIG on the endoplasmic reticulum membrane. When intracellular cholesterol decreases, the SREBP-SCAP complex detaches from INSIG and migrates into the Golgi apparatus. Subsequently, SREBP is cleaved by Site- 1 protease (S1P) and Site-2 protease (S2P). The SREBP that migrated into the nucleus binds to sterol regulatory element (SRE) and promotes the transcription of the target gene.

The suppressive effects of statins on cardiovascular diseases have been demonstrated in numerous studies. Some of these studies have reported that the suppressive effects of statins on cardiovascular diseases are not necessarily correlated with the cholesterol-lowering effect; hence, attention should be given statin effects different from the cholesterollowering effect (pleiotropic effects) $[22,23]$. Such pleiotropic effects include cardiovascular effects, such as antioxidative, antithrombotic, and functional improvement effects on endothelial cells, and noncardiovascular effects, such as anti-inflammatory and anticarcinogenic effects. Multiple studies have indicated that pleiotropic effects of statins are partially attributed to the statin-mediated suppression of isoprenoid synthesis [24, 25]. Isoprenoids are intermediates of the cholesterol biosynthesis pathway. Thus, statins suppress not only the synthesis of cholesterol but also that of isoprenoids.

Isoprenoids are critical molecules in maintaining cell functions, such as electron transport and protein functional regulation. The activity of Rho and Ras families of low molecular weight G-proteins (small G-proteins) is modulated through post-translational modification with isoprenoid biosynthesis intermediate metabolites, such as farnesyl pyrophosphate (FPP) and geranylgeranyl pyrophosphate (GGPP) [26]. The geranylgeranylation of Rho family proteins by GGPP modulates their activity by determining their intracellular localization. Statins suppress Rho activation by inhibiting GGPP production, thereby regulating the expression of vasoactive substances, such as endothelin-1 [27], vascular endothelial growth factor [27], angiotensin II receptor type-1 [28], and endothelial 
nitric oxide synthase (eNOS) [29]. Additionally, the activity of transcriptional factors, such as nuclear factor-kappa B, Kruppel-like factor 2, and peroxisome proliferator-activated receptor, is regulated as part of the expression mechanism underlying the anti-inflammatory effect of statins [30-32]. Furthermore, Rac, which belongs to Rho family proteins, is involved in the activation of nicotinamide adenine dinucleotide phosphate oxidase and the production of superoxides. Therefore, the statin-mediated suppression of Rac activation may stabilize eNOS and decrease oxidative stress [33, 34]. Meanwhile, the FPP-mediated farnesylation of Ras regulates Ras activation by controlling its migration from the cytoplasm to the cell membrane. Ras has been revealed to activate certain intracellular signaling pathways, such as MAP kinase and PI3K pathways, and play a pivotal role in the regulation of cell proliferation, movement, death, and other cellular phenomena. Several previous reports have indicated that statin-mediated Ras suppression regulates cellular proliferation and cell death, consequently leading to an antitumor effect $[35,36]$. Additionally, statins exhibit the antitumor effect by inhibiting Hippo-Yap/TAZ pathway, which is involved in cellular proliferation [37-39].

As mentioned above, statins suppress the production of intermediate metabolites of isoprenoid biosynthesis, such as GGPP and FPP, by inhibiting the cholesterol biosynthesis pathway, consequently suppressing the activation of small G-proteins. Small G-proteins play important roles in many systems that regulate cellular functions, and these regulatory effects are partially attributed to the pleiotropic effects of statins (Figure 2).

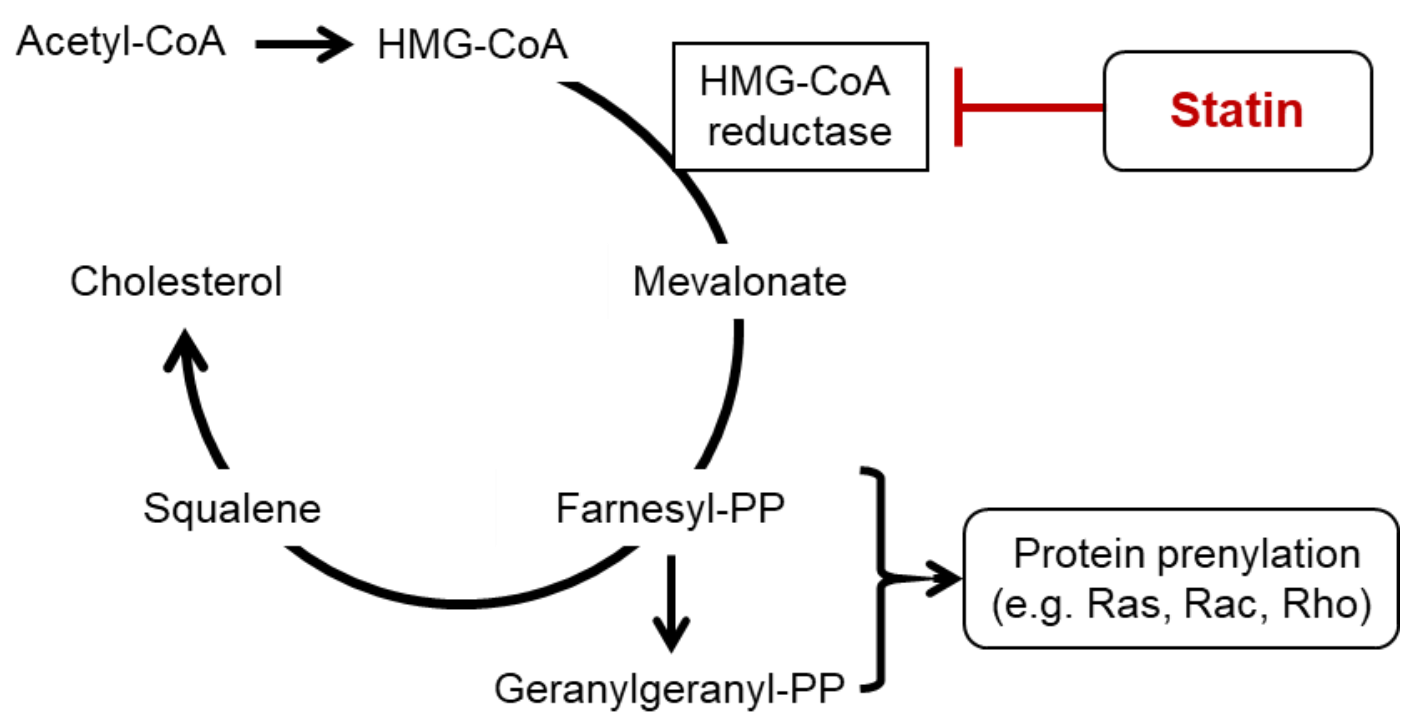

Figure 2. Action of cholesterol and statins on the isoprenoid biosynthesis pathway

Statins, which inhibit -hydroxy-3-methylglutaryl-coenzyme A (HMG-CoA) reductase, suppress not only the biosynthesis of cholesterol but also that of isoprenoids. Low molecular weight G-proteins (small G-proteins) of the Rho and Ras families are subject to activation modulation through post-transcriptional modification with isoprenoid biosynthesis intermediate metabolites, such as farnesyl pyrophosphate (farnesyl-PP) and geranylgeranyl pyrophosphate (geranylgeranyl-PP). Small G-proteins regulate cellular proliferation, cellular differentiation, gene expression, and cell movement, among other processes. These regulatory effects are partially attributed to the pleiotropic effects of statins.

\section{Statins and cardiovascular diseases}

An association between dyslipidemia and cardiovascular diseases has been established [2-8]. Evidence on LDL-C and cardiovascular disease is more abundant than other dyslipidemias. Many epidemiological studies in Europe and the United States, including the Framingham study, have shown that higher LDL-C levels increase the incidence and mortality of coronary artery disease [40]. 
Statins are HMG-CoA reductase inhibitors that reduce cholesterol synthesis in the liver. By reducing intracellular cholesterol, statins increase the expression of LDL receptor on the surface of the liver. As a result, LDL uptake from the blood is increased, and plasma levels of other ApoB-containing lipoproteins, including LDLs, chylomicrons, very lowdensity lipoproteins (VLDLs), lipoprotein (Lp)(a), and intermediate-density lipoproteins. Since the 1990s, large-scale clinical trials, conducted mainly in Europe and the United States, have demonstrated that lipid-lowering therapy with statins reduces cardiovascular events. In 2005, Cholesterol Treatment Trialists' (CTT) collaborators reported that a one mmol-reduction $(38.7 \mathrm{mg} / \mathrm{dl}$ ) of LDL-C reduced major cardiovascular events (that include non-fatal myocardial infarction [MI], coronary heart disease death, coronary revascularization, and stroke) by $21 \%$, regardless of the baseline LDL-C value [41]. This trial is a metaanalysis of 14 RCTs comparing statins and placebo groups, showing the efficacy of statins for cardiovascular diseases. The drugs used in this study included simvastatin, lovastatin, pravastatin, fluvastatin, and atorvastatin. In many cases, standard statins were used. Moreover, in 2010, CTT collaborators reported that a meta-analysis of all 26 randomized trials showed similar results to those in 2005 . It showed to be $22 \%$ suppressed and $10 \%$ reduction in total mortality. In addition, more intensive statin regimens resulted in a $15 \%$ greater reduction in major cardiovascular adverse events than those given in less intensive regimens. In other words, it was suggested that the hypothesis "the lower, the better" is correct to reduce the risk of cardiovascular events for LDL-C [42]. In 2019 ESC/EAS guidelines for the management of dyslipidemias, as a secondary prevention, they recommended for patients with very high risk (defined as documented ASCVD [atherosclerotic cardiovascular disease], diabetes mellitus [DM] with target organ damage, severe chronic kidney disease [CKD], a calculated systematic coronary risk evaluation of $>10 \%$ for 10 year risk of fatal cardiovascular disease [CVD], or familial hypercholesterolemia [FH] with ASCVD risk factor), an LDL-C reduction of $>50 \%$ from baseline and an LDL-C goal of $<1.4 \mathrm{mmol} / \mathrm{L}(<55 \mathrm{mg} / \mathrm{dL})$. Then, they also recommended LDL-C reduction of $>50 \%$ from baseline and an LDL-C goal of $<1.8 \mathrm{mmol} / \mathrm{L}(<70 \mathrm{mg} / \mathrm{dL})$ for patients with high risk, an LDL-C goal of $<2.6 \mathrm{mmol} / \mathrm{L}(<100 \mathrm{mg} / \mathrm{dL})$ for moderate risk, an LDL-C goal of $<3.0 \mathrm{mmol} / \mathrm{L}$ $(<116 \mathrm{mg} / \mathrm{dL})$ for low risk [43].

Different types of statins have different degrees of LDL-C reduction, and different statin doses have different rates of this reduction. High-intensity regimens are defined as doses of statins that reduce LDL-C by $50 \%$ on average, and medium-intensity therapy is defined as doses that reduce LDL-C by 30\%-50\% [44]. However, the degree of statin-induced LDL-C reduction varies from person to person and is affected by genetic background and medication compliance. Some people cannot tolerate and continue taking appropriate doses, requiring a change to a non-statin agent to improve dyslipidemia. Also, statins improve hypertriglyceridemia and reduce triglyceride (TG) levels by $10 \%-20 \%$ of baseline values. Particularly, strong statins (rosuvastatin, pitavastatin, and atorvastatin) have a high TG-lowering effect [45]. The mechanism of the TG-lowering effect of statins is unclear, but it seems that an increase in lipoprotein metabolism is involved. It is said that an increase in the VLDL uptake rate in hepatocytes and a decrease in VLDL production rate are involved. The rate of VLDL decrease may depend on VLDL concentration before the treatment [46]. In a meta-analysis, statin dose changed the degree of high-density lipoprotein-cholesterol (HDL-C) level elevation. by using statins, the rate of HDL-C increase has been shown to be less than $10 \%$, but the rate of ApoB-containing protein decrease has been large, and it is possible that the HDL-C increase is involved in these results [47]. In 2016, I Ford analyzed the data of the West of Scotland Coronary Prevention Study and verified the efficacy of statins for non-DM patients with a 10 -year risk of ASCVD < $7.5 \%$. With a duration of over 20 years, an $18 \%$ risk reduction of all-cause death was shown [48]. Although statins are effective for preventing ASCVD in adults aged 75 years and older, subgroup analysis of heart failure and hemodialysis patients has failed to show their effectiveness [42].

It has also been suggested that the preventive effect of statins for ASCVD may not be limited to lowering cholesterol. In the Jupiter trial, rosuvastatin reduced cardiovascular 
events in patients with normal LDL-C and high C-reactive protein (CRP) [49]. Independent of LDL-C lowering, statins have been suggested to inhibit the development of cardiovascular diseases through anti-inflammatory, antioxidant, vascular endothelial functionimproving, plaque-stabilizing, and platelet aggregation-inhibiting effects [10-12].

For patients with a high risk of cardiovascular diseases, the benefits of statin therapy outweigh the risks. The risk of statin-induced severe muscle damage, including scrotum lysis, is less than $0.1 \%$, and the risk of severe hepatotoxicity is approximately $0.001 \%$. The risk of newly diagnosed statin-induced DM is about $0.2 \%$ per year of treatment, depending on the underlying risk of diabetes in a study population. Statins may increase the risk of hemorrhagic stroke in patients with cerebrovascular diseases. However, statins significantly reduce the risk of atherothrombotic stroke, and thus, total stroke and other adverse cardiovascular events. To date, there is no convincing evidence on a causal link between statins and cancer, cataracts, cognitive dysfunction, peripheral neuropathy, erectile dysfunction, or tendinitis [50].

\section{Statins and cerebrovascular diseases}

The preventive effect of statins on atherothrombotic stroke is well established, but statins can influence other cerebrovascular diseases. Thus, statins have many neurological effects in addition to lowering cholesterol. Here, we discuss the effects of statins on cerebrovascular disease from several aspects.

\subsection{Cerebral infarction}

Statins are strongly associated with cerebrovascular diseases, especially cerebral infarction. Many large clinical trials have been conducted, showing the statins positive effect on stroke. Representative studies include Cholesterol Recurrent Events (CARE) Study [51], Long-Term Intervention with Pravastatin Ischemic Disease (LIPID) Study [52], and Heart Protection Study (HPS) [53], all showing a reduction in the incidence of stroke or cerebral infarction. In addition, the Stroke Prevention by Aggressive Reduction of Cholesterol (SPARCL) study [54] showed the efficacy of statins in patients with stroke or transient ischemic attack. These results have been attributed to the importance of the cholesterol-lowering effect, which is the primary effect of statins $[53,55]$. However, recent studies have shown that cholesterol reduction in stroke is not the major factor, highlighting the importance of pleiotropic effects [56-58]. Statins influence intracellular signaling, improve vascular endothelial function, inhibit thrombus formation, and exert anti-inflammatory and antiangiogenic effects. Statin treatment is essential for patients with carotid artery stenosis, as the pleiotropic effect stabilizes the carotid atherosclerotic plaque [59]. This finding has been confirmed by the results of the Japan Statin Treatment Against Recurrent Stroke (J-STARS) study, which showed that low-dose statin reduces the occurrence of stroke due to larger artery atherosclerosis [60]. Although statins have been well studied for the primary and long-term secondary prevention of stroke, their use in the acute phase is controversial. Large retrospective studies have shown that early resumption of statins contributes to improved survival in patients using statins prior to stroke onset [61]. On the other hand, the benefit of statin in the acute phase of stroke was not clear in the Administration of Statin on Acute Ischemic Stroke Patient Trial (ASSORT) [62]. However, recent advances in stroke treatment have supported the usefulness of statins as an early intervention. A systematic review and meta-analysis of intravenous thrombolysis, one of the core components of early treatment, has shown that post-treatment use of statins is associated with reduced intracerebral hemorrhage and mortality. Furthermore, in mechanical thrombectomy, preoperative and long-term postoperative use of statins has been suggested to reduce the risk of arterial re-occlusion [63-65]. In addition, experiments on animals have shown that statins can protect arterial intimal damage after endovascular mechanical thrombectomy using stent retrievers [66]. The pleiotropic properties of statins suggest that they provide benefits in many other aspects besides post-stroke prevention. The anti-inflammatory and neuroprotective effects of statins can reduce the infarct 
volume. This result is supported by a meta-analysis of stroke imaging analysis, showing that suppressing oxygen glucose deprivation-induced activated microglial cells and reticulum stress by autophagy inhibition are associated with the study [67-69]. The inhibition of aquaporin 4 (AQP4) expression by statins has also been shown to contribute to the reduced volume of cerebral infarction by suppressing brain edema [70]. In addition, recent studies have shown that the neuroinflammatory suppressive effect of statins can inhibit early and long-term epileptic seizures after stroke [71-73]. Therefore, statin therapy should not be withdrawn in patients previously taking statins, and patients not previously treated with statins should start receiving statins from the early stage of stroke.

\subsection{Intracerebral hemorrhage}

The effect of statins on intracerebral hemorrhage (ICH) has been controversial, as previous epidemiological studies have shown that hypocholesterolemia may cause increasing ICH. Also, the SPARCL study showed an increased occurrence of a cerebral hemorrhage. This is related to the facts that cholesterol is important for maintaining the structure of blood vessels and that statins suppress platelet aggregation. However, recent studies have shown that statins do not increase the risk of hemorrhage, further suggesting their beneficial effects in ICH. A large meta-analysis of 42 trials revealed no apparent association between statins and risk of $\mathrm{ICH}$ and showed a reduction in stroke and cerebral infarction [74]. Although several studies have been conducted on statin use and cerebral microbleeds (CMBs) formation, which are related to $\mathrm{ICH}$, there is no clear association [75, 76]. In addition, a large prospective cohort study suggested that statins might reduce the risk of ICH [77]. The multifaceted effects of statins may reduce brain damage in patients after ICH and improve their prognosis. Several animal studies have shown that statins have many neuroprotective effects, including protection of the blood-brain barrier (BBB), inhibition of inflammatory cytokines, anti-apoptotic effect, and reduction of brain edema after ICH [78-82]. Although the evidence for statin use in $\mathrm{ICH}$ remains unclear, the risks of their use have been low, and there is no need to avoid their use intensively.

\subsection{Cerebral aneurysm and subarachnoid hemorrhage}

The use of statins in patients with acute subarachnoid hemorrhage has been studied extensively because of their potential effectiveness in treating cerebral vasospasm and delayed ischemic neurological deficit (DIND). However, there is still no consensus on statin use, and their clinical usefulness remains controversial. Several animal studies suggested that statins improve early brain damage and reduce cerebral vasospasm after subarachnoid hemorrhage through their anti-inflammatory, anti-apoptotic, and AQP4 expressioninhibitory effects [83-85]. Several clinical trials showed that statins reduce cerebral vasoconstriction and DIND [86-89], and some meta-analyses also showed this finding [90-92]. In contrast, there are some studies that have not shown the clear efficacy of statins $[93,94]$. The pleiotropic effect of statins may potentially prevent brain damage after subarachnoid hemorrhage; thus, future large-cohort studies are desirable. In addition, recent research has focused on the rupture-preventive statin effects on unruptured cerebral aneurysms. Although several retrospective studies showed that statins reduce aneurysm rupture through their anti-inflammation and endothelial protective effects [95, 96], the first prospective randomized controlled trial did not show a clear significant difference [97], requiring additional studies.

\section{Statins and cancer}

In addition to the cholesterol-lowering effect, statins are reported to have anti-inflammatory and antitumor effects (statin-associated pleiotrophy). Basic research suggests that statins cause pro-apoptotic, growth-inhibitory, and pro-differentiation effects in various malignancies [13]. If they are effective against tumors, the statins can be more 
reasonable and are better tolerated than traditional chemotherapeutic agents. Then, statins are investigated whether they can be used to prevent or treat cancer alone or in combination with other drugs. This chapter summarizes the pros and cons of the antitumor effect of statins (Table 1 ).

Table 1. Pros and cons of statin use for patients with malignant tumors

\begin{tabular}{|c|c|}
\hline Pros & Cons \\
\hline $\begin{array}{l}\text { Statins are economically reasonable and well- } \\
\text { tolerated compared to conventional chemother- } \\
\text { apeutic agents. }\end{array}$ & $\begin{array}{l}\text { Much evidence was derived from cardiovascular dis- } \\
\text { ease studies, in which statins are off-label use for ma- } \\
\text { lignancies. }\end{array}$ \\
\hline Hypocholesterolemia is probably a risk factor. & $\begin{array}{l}\text { Patients with mild to moderate hypercholesterolemia } \\
\text { tend to have favorable outcomes. }\end{array}$ \\
\hline Favorable for malignancies? & Carcinogenic? \\
\hline There are many observational studies. & Biases may not always be excluded from the studies. \\
\hline Statins improve cardiovascular outcomes. & $\begin{array}{l}\text { Lipid-lowering drugs, accidentally including statins, } \\
\text { may not necessarily improve all-cause mortality. }\end{array}$ \\
\hline
\end{tabular}

\subsection{Effective molecular markers}

Some authors discussed how to detect statin-vulnerable tumors. Statin-vulnerable molecular features include mesenchymal cell state, sensitizing molecular mechanisms, such as p53 mutation, $\mathrm{t}(4 ; 14)$ translocation, and impaired SREBP-mediated feedback response [98], mevalonate pathway genes, the Yes-associated protein (YAP)/ transcriptional coactivator with PDZ-binding motif (TAZ) transcriptional regulators [99], and cancer stem cell maintenance among others [100-102].

\subsection{Clinical studies}

\section{Breast cancer: One of the promising scenarios}

Metabolic syndrome, including hypercholesterolemia, can harm the prognosis of breast cancer patients [103]. Although meta-analyses did not necessarily demonstrate the antitumor effect of statins against breast cancer [104], some nationwide cohort studies supported the protective effect of statins regarding breast cancer-related incidence and mortality [105, 106]. Eliminating the possibility of immortal time bias and selection bias (see Limitations below), Nowakowska et al. have reported that statins used for triple-negative breast cancer (TNBC) improve overall survival (OS) in stage I to III patients [107]. Estrogen receptor (ER)-negative breast cancer cells are sensitive to statin exposure [108]. An increase of mesenchymal cell marker, vimentin, or decrease of the epithelial marker, E-cadherin, is sensitive to statins $[109,110]$. It is speculated that epithelial-mesenchymal transition-inducing cells are highly sensitive to statin treatment, which may suppress the metastatic potential of breast cancer $[98,111]$. In a phase II study, fluvastatin reduced proliferation and increased apoptosis in women with ER-negative high-grade breast cancer [112]. High-dose atorvastatin induces anti-proliferative effects through upregulation of tumor suppressor p27 (cyclin-dependent kinase 1B) and down-regulation of oncogene cyclin D1 in phase II study of 42 patients with breast cancer [113].

There are several phase II randomized clinical trials (RCTs) that have investigated statin use in cancer. Chemo-sensitizing effect was investigated in 82 metastatic breast cancer patients, but carboplatin and vinorelbine plus simvastatin did not improve objective response rate (ORR), toxicity, and OS compared with carboplatin and vinorelbine alone. High-sensitivity CRP (hsCRP) and lactate dehydrogenase (LDH) are described as prognostic factors in breast cancer patients [114]. A trend for better activity and tolerability is observed in 66 patients with locally advanced breast cancer; however, fluorouracil, adriamycin, and cyclophosphamide (FAC) plus simvastatin did not statistically improve ORR 
and OS compared with FAC alone. Human epidermal growth factor receptor-related 2 (HER2) expression is the factor related to therapeutic response in that study [115]. However, the study populations were not stratified with molecular markers. Statin safety has been partially warranted concerning skin toxicity and cardiotoxicity protection in RCTs on breast cancer patients [116-118]. Therefore, statin administration is a promising approach for tumors with effective molecular markers and without sufficient treatment options, such as ER-negative breast cancer and TNBC. Statins have also been speculated to be effective against ER-positive breast cancer for other reasons [99]. In October 2021, several phase III prospective RCTs can be searched at clinicaltrials.gov.

\section{Leukemia}

A meta-analysis suggested the preventive effect of statins for leukemia and non-Hodgkin lymphoma [119]. In a phase I study, idarubicin and high-dose cytarabine plus pravastatin were administered in 15 newly diagnosed and 22 salvage patients with acute myeloid leukemia (AML) harboring unfavorable or intermediate prognosis cytogenetics. Compared with a historical group, complete remission was obtained in 11 of 15 new patients and 9 of 22 salvage patients. These are encouraging response rates [120]. In a phase II trial, idarubicin, cytarabine, and pravastatin improved the response rate compared with historical control in relapsed AML [121]. However, the chemotherapy plus pravastatin regimen did not meet the prespecified efficacy criteria in 24 patients with newly diagnosed AML [122].

\section{Multiple myeloma}

Meta-analyses suggested the preventive effect of statins for multiple myeloma [123, 124]. A pilot phase II trial revealed that six patients with refractory multiple myeloma to whom simvastatin was administered showed a reduction of chemotherapy resistance compared to 10 patients without simvastatin use [125]. Lovastatin plus thalidomide-dexamethasone prolonged OS and progression-free survival (PFS) compared to thalidomidedexamethasone alone in a phase II study [126].

\section{Esophageal cancer}

Meta-analysis findings suggested the pleiotropic effect of statins in esophageal cancer $[127,128]$. An RCT supported the feasibility of the one-year simvastatin administration for patients with esophageal cancer who had undergone esophagectomy but did not conclude the survival outcomes [129]. Statins may also have a protective effect for acute lung injury after esophagectomy [130].

\section{Gastric cancer}

Meta-analysis findings presented statin-associated pleiotropy in gastric cancer [131133]. The effect of statins revealed the same tendency even when the effect of Helicobacter eradication was considered [134]. In several phase II or III RCTs, lovastatin with ubiquinone was ineffective for patients with advanced gastric adenocarcinoma [135], epirubicin, cisplatin, and capecitabine plus pravastatin did not improve PFS at six months compared with the chemotherapy alone [136], and capecitabine and cisplatin plus simvastatin did not increase PFS compared with capecitabine and cisplatin alone in advanced gastric cancer [137]. Statins were reported to increase the eradication rate of Helicobacter pylori in RCTs, which is favorable for gastric cancer prevention [138, 139].

\section{Colorectal cancer}

Epidemiological studies suggested the pleiotropic effect of statins on colorectal cancer $[140,141]$. A retrospective cohort study revealed that preoperative statin therapy displays a strong association with reduced postoperative mortality following surgical resection for rectal cancer [142]. On the other hand, statin use at the time of diagnosis was not associated with increased PFS and OS in KRAS-mutant patients treated with chemotherapy and bevacizumab plus cetuximab [143]. In a prospective observational study, statin use during and after adjuvant chemotherapy was not associated with improved OS in patients with stage III colon cancer after curative resection, regardless of KRAS mutation status [144]. Leucovorin, 5-fluorouracil, irinotecan (FOLFIRI)/capecitabine, and irinotecan (XELIRI) plus simvastatin did not increase OS and PFS compared with FOLFIRI/XELIRI 
alone in metastatic colorectal cancer in a phase III RCT [145]. Simvastatin effect on longcourse fluoropyrimidine-based preventive chemoradiotherapy is being studied in a phase II RCT [146]. The preventive effect of statins on colorectal cancer has also been investigated, but no consensus has been reached yet [147].

\section{Hepatocellular carcinoma}

A meta-analysis described statin-associated pleiotropy in hepatocellular carcinoma [148-150]. There are several phase II or III RCTs that studied this effect. Sorafenib plus pravastatin did not improve time to progression (TTP), PFS, and OS compared with sorafenib alone [151, 152], but improved TTP in another study [153]. In a study of transcatheter arterial embolization followed by fluorouracil, the addition of pravastatin prolonged OS compared with the standard therapy alone in advanced hepatocellular carcinoma [154]. Atorvastatin for preventing hepatocellular carcinoma recurrence after curative treatment is being investigated in an RCT (NCT03024684).

\section{Pancreatic cancer}

Epidemiological studies suggested the pleiotropic effect of statins on pancreatic cancer $[155,156]$. However, gemcitabine plus simvastatin did not decrease TTP compared with gemcitabine alone in advanced pancreatic cancer [157].

\section{Lung cancer}

Although meta-analysis did not demonstrate statin-associated pleiotropy against lung cancer [158] among lipid-lowering medication users in a nationwide study, adherence was inversely associated with reduced cancer-specific mortality in lung cancer [159]. An exploratory analysis of the Canakinumab Anti-inflammatory Thrombosis Outcome Study, in which a monoclonal antibody targeting interleukin-1-beta was studied primarily to reduce major adverse cardiovascular events, indicated that the drug is associated with a significant reduction of lung malignancy [160]. Recent epidemiological studies have also suggested that the addition of statins to tyrosine kinase inhibitors (TKI) targeting epidermal growth factor receptor (EGFR) may be effective [161, 162]. Statins were associated with better clinical outcomes in malignant pleural mesothelioma and advanced nonsmall-cell lung cancer patients treated with programmed cell death-1 (PD-1) inhibitors in a retrospective study [163]. Standard chemotherapy plus pravastatin did not offer additional benefit compared with chemotherapy alone in patients with small-cell lung cancer [164]. Afatinib plus simvastatin did not improve response rates compared with afatinib alone in patients with non-adenocarcinomas [165], but gefitinib plus simvastatin were reported to demonstrate higher tumor response rates and longer PFS compared to gefitinib alone in patients with EGFR wild type non-adenocarcinomas [166].

\section{Renal cell carcinoma}

Although a meta-analysis did not demonstrate pleiotropy of statins in renal cell carcinoma [167], the hypothesis has not been conclusive [168, 169]. Statins were reported to be favorable for patients treated with sunitinib or immune checkpoint inhibitors [170, 171]. Association between statin use and a reduced risk of progression and OS has been inconsistent in RCTs on patients with localized or locally advanced renal cell carcinoma after surgery $[172,173]$.

\section{Bladder cancer}

Although meta-analysis findings did not demonstrate the pleiotropic effect of statin in bladder cancer [174], the hypothesis has not been conclusive [175]. A large populationbased study revealed that statin users have better OS than nonusers with non-muscleinvasive bladder cancer but did not have a chemopreventive effect [176]. The chemopreventive effect of statin in bladder cancer remains to be investigated [177].

\section{Prostate cancer}

Serum cholesterol levels and metabolic syndrome may be potential risk factors for prostate cancer, but this suggestion remains inconclusive [178-180]. Many studies described the possibility of statin-associated pleiotropy in prostate cancer [174, 181]. However, in a retrospective analysis, statin administration improved biochemical PFS but did not prolong OS in patients with prostatic cancer who had undergone radical 
prostatectomy [182]. A brachytherapy investigation suggested that statins, especially atorvastatin, may improve most clinical presentations with a nonsignificant improvement in 8-year biochemical PFS [183]. Postoperative treatment with atorvastatin might have contributed to the earlier recovery of erectile function after nerve-sparing radical retropubic prostatectomy [184]. The chemo-preventive effect of statin in prostate cancer remains to be investigated $[185,186]$. An RCT was designed to assess the potential synergies of metformin and atorvastatin for prostate cancer but has been terminated due to the low incidence of eligible patients [187].

\section{Malignant melanoma}

Some observational studies and secondary analysis indicated statin advantages in melanoma [188-190]. However, a meta-analysis of 20 RCTs of statins and fibrates for heart disease prevention found favorable but no statistically significant effect for malignant melanoma [191]. In a randomized phase II clinical trial, a 6-month course of lovastatin for clinically atypical nevi did not induce favorable changes compared with placebo [192].

\subsection{Limitations}

There are some limitations to this study.

\section{Drawbacks of epidemiological studies}

Epidemiological studies are useful and important, but the potential for selection bias and immortal time bias must be considered [193, 194]. No matter how well-designed epidemiological studies are, one is unable to explain all potential sources of confounding and bias, and confounding factors cannot always be removed from cohort observational studies

\section{Off-label use}

In many observational and retrospective clinical studies, at least nominally, statins were prescribed for the primary prevention for patients with hypercholesterolemia or secondary prevention of coronary artery disease, stroke, and any other cardiovascular diseases. Therefore, such statin administration was off-label use for malignancies.

\section{Natural history: is hypocholesterolemia or hypercholesterolemia harmful to malignan-} cies?

The Framingham study reported that after the age of 50 years, there is no increased overall mortality with either high or low serum cholesterol levels, and the association of mortality with cholesterol values might be confounded by the diseases predisposing to death [195]. Both hypocholesterolemia and hypercholesterolemia are reported to be harmful to malignancies or all-cause mortality [196-198]. The population with mildly or moderately high blood cholesterol levels (from 211 to $251 \mathrm{mg} / 100 \mathrm{ml}$, for example) tends to have a better prognosis [198]. This tendency is also observed in a statin-administered group [199]. Patients with coronary artery disease or statin-eligible hypercholesterolemia have a high incidence of cancer [200, 201]. In a meta-analysis of stroke recurrence, although metabolic syndrome was associated with all-cause mortality, the role of its components, such as hypercholesterolemia, in predicting all-cause mortality was not statistically significant [202]. Additionally, about $40 \%$ of untreated patients with FH, who were carriers of the $V 408 M$ mutation or Afrikaner-2 mutation in exon 9 of the LDL receptor gene, reached a normal life span. At the end of the 19th century, the standardized mortality ratio of this population was lower than that of the general population [203]. Therefore, although the results of previous studies remain inconsistent, hypocholesterolemia and hypercholesterolemia probably seem to be correlated with tumors. Some cancers are reported to induce hypocholesterolemia [204], but others are not [205]. However, the causal relationships remain unknown, and further studies are needed. It should be noted that the population with mild to moderate hypercholesterolemia tends to have a favorable prognosis for the incidence and/or mortality of cancer and/or all-cause mortality.

Do statins and lipid-lowering drugs have carcinogenicity?

A possibility of the carcinogenic effect of statins has been described in some observational studies on breast cancer [206], lymphoid malignancies [207], prostate cancer [208], 
bladder cancer [209], any malignancies [210], cancer in the elderly patients [211, 212], and in a meta-analysis or commentaries [199, 213, 214]. However, other studies found no such effect [215-217]. Newman and Hulley summarized that clofibrates and statins cause cancer in rodents, in some cases at levels of animal exposure close to those prescribed to humans, compared to a few antihypertensive drugs. However, this result of animal experiments could be directly extrapolated to humans, and evidence of carcinogenicity of lipidlowering drugs from clinical trials in humans is inconclusive because of inconsistent results and insufficient duration of follow-up [218]. Recently, Improved Reduction of Outcomes: Vytorin Efficacy International Trial (IMPROVE-IT) has demonstrated that ezetimibe, a non-statin drug inhibiting the intestinal absorption of cholesterol by targeting Nieman-Pick C1-Like 1 transmembrane protein, added to simvastatin improved the outcome of the patients with coronary artery disease [219]. However, the Simvastatin and Ezetimibe in Aortic Stenosis (SEAS) trial in patients with aortic valve stenosis showed an unexpected increase in cancer incidence during a median follow-up of 52.2 months [220]. Post-hoc analysis of IMPROVE-IT group and SEAS registry-based observational study after 21 months follow-up did not show an increase in cancer incidence and mortality, respectively [221, 222]. The simvastatin implication remains to be clarified. The presence or absence of a harmful effect of ezetimibe on cancer is currently controversial.

As discussed above, the administration of lipid-lowering drugs may be just a confounding factor, and long-term survivors with mild to moderate hypercholesterolemia may tend to develop tumors. In short, long-term clinical trials and careful surveillance is still needed to determine whether cholesterol-lowering drugs cause cancer in humans [218].

\section{Do statins and/or lipid-lowering drugs improve the true endpoint, all-cause mortality?}

Historically, clofibrates reduced the risk of myocardial infarction but tended to increase cancer, although not significantly, and failed to reduce all-cause mortality [214]. Recently, in the first randomized controlled study, evolocumab, proprotein convertase subtilisin-kexin type 9 (PCSK9) inhibitor, has significantly improved the recurrence of cardiovascular disease but without significant difference in all-cause mortality [223, 224]. Statins have been reported to improve all-cause mortality in a large-scale meta-analysis; however, their effect on cardiovascular disease has been the best factor, and they do not always improve cancer survival [42]. Even if cancer survival is improved, statins may not necessarily improve OS compared with medical advice alone [225].

\subsection{Perspective}

Therefore, it is indispensable to verify statins antitumor effect in prospective controlled RCTs to clarify their true effect, as frequently pointed out by the authors of many basic, observational, and clinical studies. Their effect appears promising to stratify with molecular markers and treat in the direction of precision medicine, especially for tumors with few treatment options [98]

\section{Conclusion}

This review described the pharmacological action of statins, focusing on the aspect of 'beyond lipid-lowering.' Furthermore, we discussed the recent evidence on the effects of statins on cardiovascular and cerebrovascular diseases and cancer. Statins suppress the production of intermediate metabolites of isoprenoid biosynthesis, such as GGPP and FPP, by inhibiting the cholesterol biosynthesis pathway, consequently suppressing the activation of small G-proteins. Small G-proteins play important roles in many systems that regulate cellular functions, and these regulatory effects are partially attributed to the pleiotropic effects of statins. The preventive effect of statins on cardiovascular diseases and atherothrombotic stroke is well established mainly due to cholesterol lowering. But statins can influence other cerebrovascular diseases probably due to independent of cholesterol lowering. Statins have been suggested to inhibit the development of cardiovascular diseases through anti-inflammatory, antioxidant, vascular endothelial function- 
improving, plaque-stabilizing, and platelet aggregation-inhibiting effects. Several studies have shown that statins have many neuroprotective effects, including protection of the $\mathrm{BBB}$, inhibition of inflammatory cytokines, anti-apoptotic effect, and reduction of brain edema. Basic research suggests that statins cause pro-apoptotic, growth-inhibitory, and pro-differentiation effects in various malignancies [13]. If they are effective against tumors, the statins can be more reasonable and are better tolerated than traditional chemotherapeutic agents. Then, statins are investigated whether they can be used to prevent or treat cancer alone or in combination with other drugs. It is indispensable to verify statins antitumor effect in prospective controlled RCTs to clarify their true effect, as frequently pointed out by the authors of many basic, observational, and clinical studies. Although many animal model and non-randomized data on the pleiotropic effects of statins seems promising, proper long term clinical trials and results are necessary to evaluate their therapeutic efficacy on cardiovascular and cerebrovascular diseases, and cancer. It is also crucially important from the perspective of drug-repositioning [226].

Author Contributions: Conceptualization, Y.M. and S.N.; formal analysis, Y.M. and S.N.; writingoriginal draft preparation, Y.M., S.N., K.U., T.F. and K.O.; writing-review and editing, Y.M.; supervision, N.M. and K.T.; project administration, Y.M.; funding acquisition, Y.M. all authors have read and agreed to the published version of the manuscript.

Funding: This study was funded by JSPS and the Hungarian Academy of Sciences under the JapanHungary Research Cooperative Program (to Y.M.), Grants-in-Aid for Scientific Research (Fostering Joint International Research) 20KK0254 (to Y.M.), Grants-in-Aid for Scientific Research (C) 19K09531 (to Y.M.), (C) 20K09351(to Y.M.) and Fukuoka University (Grant No. 211032).

Institutional Review Board Statement: Not applicable.

Informed Consent Statement: Not applicable.

Data Availability Statement: Data sharing not applicable.

Acknowledgements: We wish to thank Kei Sato, Yuki Matsunaga, Yusuke Iki, Nobutaka Horie, Tsuyoshi Izumo, Takeo Anda, and Takayuki Matsuo for providing insight and expertise that greatly assisted the research, although they may not agree with all the interpretations/conclusions of this paper. We also thank Enago (www.enago.jp) for the English language review.

Conflicts of Interest: The authors declare no conflict of interest.

\section{References}

[1] M. Schachter, Chemical, pharmacokinetic and pharmacodynamic properties of statins: an update, Fundam Clin Pharmacol 19(1) (2005) 117-25.

[2] A. Patel, F. Barzi, K. Jamrozik, T.H. Lam, H. Ueshima, G. Whitlock, M. Woodward, C. Asia Pacific Cohort Studies, Serum triglycerides as a risk factor for cardiovascular diseases in the Asia-Pacific region, Circulation 110(17) (2004) 2678-86.

[3] N. Sarwar, J. Danesh, G. Eiriksdottir, G. Sigurdsson, N. Wareham, S. Bingham, S.M. Boekholdt, K.T. Khaw, V. Gudnason, Triglycerides and the risk of coronary heart disease: 10,158 incident cases among 262,525 participants in 29 Western prospective studies, Circulation 115(4) (2007) 450-8.

[4] H. Iso, Y. Naito, S. Sato, A. Kitamura, T. Okamura, T. Sankai, T. Shimamoto, M. Iida, Y. Komachi, Serum triglycerides and risk of coronary heart disease among Japanese men and women, Am J Epidemiol 153(5) (2001) 490-9.

[5] S.Y. Nagasawa, T. Okamura, H. Iso, A. Tamakoshi, M. Yamada, M. Watanabe, Y. Murakami, K. Miura, H. Ueshima, G. Evidence for Cardiovascular Prevention from Observational Cohorts in Japan Research, Relation between serum total cholesterol level and cardiovascular disease stratified by sex and age group: a pooled analysis of 65594 individuals from 10 cohort studies in Japan, J Am Heart Assoc 1(5) (2012) e001974.

[6] G. Assmann, H. Schulte, A. von Eckardstein, Y. Huang, High-density lipoprotein cholesterol as a predictor of coronary heart disease risk. The PROCAM experience and pathophysiological implications for reverse cholesterol transport, Atherosclerosis 124 Suppl (1996) S11-20.

[7] A. Kitamura, H. Iso, Y. Naito, M. Iida, M. Konishi, A.R. Folsom, S. Sato, M. Kiyama, M. Nakamura, T. Sankai, et al., High-density lipoprotein cholesterol and premature coronary heart disease in urban Japanese men, Circulation 89(6) (1994) 2533-9. 
[8] T. Okamura, Y. Kokubo, M. Watanabe, A. Higashiyama, Y. Miyamoto, Y. Yoshimasa, A. Okayama, Low-density lipoprotein cholesterol and non-high-density lipoprotein cholesterol and the incidence of cardiovascular disease in an urban Japanese cohort study: The Suita study, Atherosclerosis 203(2) (2009) 587-92.

[9] M. Ahmadi, S. Amiri, S. Pecic, F. Machaj, J. Rosik, M.J. Los, J. Alizadeh, R. Mahdian, S.C. da Silva Rosa, D. Schaafsma, S. Shojaei, T. Madrakian, A.A. Zeki, S. Ghavami, Pleiotropic effects of statins: A focus on cancer, Biochim Biophys Acta Mol Basis Dis 1866(12) (2020) 165968.

[10] O. Hussein, S. Schlezinger, M. Rosenblat, S. Keidar, M. Aviram, Reduced susceptibility of low density lipoprotein (LDL) to lipid peroxidation after fluvastatin therapy is associated with the hypocholesterolemic effect of the drug and its binding to the LDL, Atherosclerosis 128(1) (1997) 11-8.

[11] S. Agewall, A. Hernberg, Atorvastatin normalizes endothelial function in healthy smokers, Clin Sci (Lond) 111(1) (2006) 87-91.

[12] S. Verma, V. Rao, R.D. Weisel, S.H. Li, P.W. Fedak, S. Miriuka, R.K. Li, Novel cardioprotective effects of pravastatin in human ventricular cardiomyocytes subjected to hypoxia and reoxygenation: beneficial effects of statins independent of endothelial cells, $\mathrm{J}$ Surg Res 119(1) (2004) 66-71.

[13] A. Sassano, L.C. Platanias, Statins in tumor suppression, Cancer Lett 260(1-2) (2008) 11-9.

[14] S.S. Mayengbam, A. Singh, A.D. Pillai, M.K. Bhat, Influence of cholesterol on cancer progression and therapy, Transl Oncol 14(6) (2021) 101043.

[15] A. Endo, M. Kuroda, K. Tanzawa, Competitive inhibition of 3-hydroxy-3-methylglutaryl coenzyme A reductase by ML-236A and ML-236B fungal metabolites, having hypocholesterolemic activity, FEBS Lett 72(2) (1976) 323-6.

[16] K. Maeda, Y. Sugiyama, Impact of genetic polymorphisms of transporters on the pharmacokinetic, pharmacodynamic and toxicological properties of anionic drugs, Drug Metab Pharmacokinet 23(4) (2008) 223-35.

[17] Y. Shitara, Y. Sugiyama, Pharmacokinetic and pharmacodynamic alterations of 3-hydroxy-3-methylglutaryl coenzyme A (HMG$\mathrm{CoA}$ ) reductase inhibitors: drug-drug interactions and interindividual differences in transporter and metabolic enzyme functions, Pharmacol Ther 112(1) (2006) 71-105.

[18] C.R. Sirtori, The pharmacology of statins, Pharmacol Res 88 (2014) 3-11.

[19] J.D. Horton, J.L. Goldstein, M.S. Brown, SREBPs: activators of the complete program of cholesterol and fatty acid synthesis in the liver, J Clin Invest 109(9) (2002) 1125-31.

[20] C. Yokoyama, X. Wang, M.R. Briggs, A. Admon, J. Wu, X. Hua, J.L. Goldstein, M.S. Brown, SREBP-1, a basic-helix-loop-helixleucine zipper protein that controls transcription of the low density lipoprotein receptor gene, Cell 75(1) (1993) 187-97.

[21] H. Shimano, R. Sato, SREBP-regulated lipid metabolism: convergent physiology - divergent pathophysiology, Nat Rev Endocrinol 13(12) (2017) 710-730.

[22] E.J. Mills, B. Rachlis, P. Wu, P.J. Devereaux, P. Arora, D. Perri, Primary prevention of cardiovascular mortality and events with statin treatments: a network meta-analysis involving more than 65,000 patients, J Am Coll Cardiol 52(22) (2008) 1769-81.

[23] A. Oesterle, U. Laufs, J.K. Liao, Pleiotropic Effects of Statins on the Cardiovascular System, Circ Res 120(1) (2017) $229-243$.

[24] N. Kavalipati, J. Shah, A. Ramakrishan, H. Vasnawala, Pleiotropic effects of statins, Indian J Endocrinol Metab 19(5) (2015) 554-

62.

[25] Q. Zhou, J.K. Liao, Pleiotropic effects of statins. - Basic research and clinical perspectives, Circ J 74(5) (2010) 818-26.

[26] J.M. Reddy, N.G.R. Raut, J.L. Seifert, D.L. Hynds, Regulation of Small GTPase Prenylation in the Nervous System, Mol Neurobiol 57(5) (2020) 2220-2231.

[27] F. Mraiche, J. Cena, D. Das, B. Vollrath, Effects of statins on vascular function of endothelin-1, Br J Pharmacol 144(5) (2005) 71526.

[28] T. Ichiki, K. Takeda, T. Tokunou, N. Iino, K. Egashira, H. Shimokawa, K. Hirano, H. Kanaide, A. Takeshita, Downregulation of angiotensin II type 1 receptor by hydrophobic 3-hydroxy-3-methylglutaryl coenzyme A reductase inhibitors in vascular smooth muscle cells, Arterioscler Thromb Vasc Biol 21(12) (2001) 1896-901.

[29] M. Sugimoto, D. Yamanouchi, K. Komori, Therapeutic approach against intimal hyperplasia of vein grafts through endothelial nitric oxide synthase/nitric oxide (eNOS/NO) and the Rho/Rho-kinase pathway, Surg Today 39(6) (2009) 459-65.

[30] M.K. Jain, P.M. Ridker, Anti-inflammatory effects of statins: clinical evidence and basic mechanisms, Nat Rev Drug Discov 4(12) (2005) 977-87.

[31] G. Martin, H. Duez, C. Blanquart, V. Berezowski, P. Poulain, J.C. Fruchart, J. Najib-Fruchart, C. Glineur, B. Staels, Statin-induced inhibition of the Rho-signaling pathway activates PPARalpha and induces HDL apoA-I, J Clin Invest 107(11) (2001) 1423-32.

[32] M. Yano, T. Matsumura, T. Senokuchi, N. Ishii, Y. Murata, K. Taketa, H. Motoshima, T. Taguchi, K. Sonoda, D. Kukidome, Y. Takuwa, T. Kawada, M. Brownlee, T. Nishikawa, E. Araki, Statins activate peroxisome proliferator-activated receptor gamma through extracellular signal-regulated kinase $1 / 2$ and p38 mitogen-activated protein kinase-dependent cyclooxygenase-2 expression in macrophages, Circ Res 100(10) (2007) 1442-51.

[33] T. Bruder-Nascimento, G.E. Callera, A.C. Montezano, E.J. Belin de Chantemele, R.C. Tostes, R.M. Touyz, Atorvastatin inhibits pro-inflammatory actions of aldosterone in vascular smooth muscle cells by reducing oxidative stress, Life Sci 221 (2019) 29-34.

[34] T. Bruder-Nascimento, G.E. Callera, A.C. Montezano, Y. He, T.T. Antunes, A. Nguyen Dinh Cat, R.C. Tostes, R.M. Touyz, Vascular injury in diabetic $\mathrm{db} / \mathrm{db}$ mice is ameliorated by atorvastatin: role of Rac1/2-sensitive Nox-dependent pathways, Clin Sci (Lond) 128(7) (2015) 411-23. 
[35] M. Baranyi, L. Buday, B. Hegedus, K-Ras prenylation as a potential anticancer target, Cancer Metastasis Rev 39(4) (2020) 11271141.

[36] G.H. Nam, M. Kwon, H. Jung, E. Ko, S.A. Kim, Y. Choi, S.J. Song, S. Kim, Y. Lee, G.B. Kim, J. Han, J. Woo, Y. Cho, C. Jeong, S.Y. Park, T.M. Roberts, Y.B. Cho, I.S. Kim, Statin-mediated inhibition of RAS prenylation activates ER stress to enhance the immunogenicity of KRAS mutant cancer, J Immunother Cancer 9(7) (2021).

[37] M. Maugeri-Sacca, M. Barba, L. Pizzuti, P. Vici, L. Di Lauro, R. Dattilo, I. Vitale, M. Bartucci, M. Mottolese, R. De Maria, The Hippo transducers TAZ and YAP in breast cancer: oncogenic activities and clinical implications, Expert Rev Mol Med 17 (2015) e14. [38] K. Tanaka, H. Osada, Y. Murakami-Tonami, Y. Horio, T. Hida, Y. Sekido, Statin suppresses Hippo pathway-inactivated malignant mesothelioma cells and blocks the YAP/CD44 growth stimulatory axis, Cancer Lett 385 (2017) 215-224.

[39] Z. Wang, Y. Wu, H. Wang, Y. Zhang, L. Mei, X. Fang, X. Zhang, F. Zhang, H. Chen, Y. Liu, Y. Jiang, S. Sun, Y. Zheng, N. Li, L. Huang, Interplay of mevalonate and Hippo pathways regulates RHAMM transcription via YAP to modulate breast cancer cell motility, Proc Natl Acad Sci U S A 111(1) (2014) E89-98.

[40] T.R. Dawber, F.E. Moore, G.V. Mann, Coronary heart disease in the Framingham study, Am J Public Health Nations Health 47(4 Pt 2) (1957) 4-24.

[41] C. Baigent, A. Keech, P.M. Kearney, L. Blackwell, G. Buck, C. Pollicino, A. Kirby, T. Sourjina, R. Peto, R. Collins, R. Simes, C. Cholesterol Treatment Trialists, Efficacy and safety of cholesterol-lowering treatment: prospective meta-analysis of data from 90,056 participants in 14 randomised trials of statins, Lancet 366(9493) (2005) 1267-78.

[42] C. Cholesterol Treatment Trialists, C. Baigent, L. Blackwell, J. Emberson, L.E. Holland, C. Reith, N. Bhala, R. Peto, E.H. Barnes, A. Keech, J. Simes, R. Collins, Efficacy and safety of more intensive lowering of LDL cholesterol: a meta-analysis of data from 170,000 participants in 26 randomised trials, Lancet 376(9753) (2010) 1670-81.

[43] F. Mach, C. Baigent, A.L. Catapano, K.C. Koskinas, M. Casula, L. Badimon, M.J. Chapman, G.G. De Backer, V. Delgado, B.A. Ference, I.M. Graham, A. Halliday, U. Landmesser, B. Mihaylova, T.R. Pedersen, G. Riccardi, D.J. Richter, M.S. Sabatine, M.R. Taskinen, L. Tokgozoglu, O. Wiklund, E.S.C.S.D. Group, 2019 ESC/EAS Guidelines for the management of dyslipidaemias: lipid modification to reduce cardiovascular risk, Eur Heart J 41(1) (2020) 111-188.

[44] S.M. Boekholdt, G.K. Hovingh, S. Mora, B.J. Arsenault, P. Amarenco, T.R. Pedersen, J.C. LaRosa, D.D. Waters, D.A. DeMicco, R.J. Simes, A.C. Keech, D. Colquhoun, G.A. Hitman, D.J. Betteridge, M.B. Clearfield, J.R. Downs, H.M. Colhoun, A.M. Gotto, Jr., P.M. Ridker, S.M. Grundy, J.J. Kastelein, Very low levels of atherogenic lipoproteins and the risk for cardiovascular events: a meta-analysis of statin trials, J Am Coll Cardiol 64(5) (2014) 485-94.

[45] Z. Reiner, Managing the residual cardiovascular disease risk associated with HDL-cholesterol and triglycerides in statin-treated patients: a clinical update, Nutr Metab Cardiovasc Dis 23(9) (2013) 799-807.

[46] A. Sharma, P.H. Joshi, S. Rinehart, K.M. Thakker, A. Lele, S. Voros, Baseline very low-density lipoprotein cholesterol is associated with the magnitude of triglyceride lowering on statins, fenofibric acid, or their combination in patients with mixed dyslipidemia, J Cardiovasc Transl Res 7(4) (2014) 465-74.

[47] P.J. Barter, G. Brandrup-Wognsen, M.K. Palmer, S.J. Nicholls, Effect of statins on HDL-C: a complex process unrelated to changes in LDL-C: analysis of the VOYAGER Database, J Lipid Res 51(6) (2010) 1546-53.

[48] I. Ford, H. Murray, C. McCowan, C.J. Packard, Long-Term Safety and Efficacy of Lowering Low-Density Lipoprotein Cholesterol With Statin Therapy: 20-Year Follow-Up of West of Scotland Coronary Prevention Study, Circulation 133(11) (2016) $1073-80$.

[49] P.M. Ridker, E. Danielson, F.A. Fonseca, J. Genest, A.M. Gotto, Jr., J.J. Kastelein, W. Koenig, P. Libby, A.J. Lorenzatti, J.G. Macfadyen, B.G. Nordestgaard, J. Shepherd, J.T. Willerson, R.J. Glynn, J.T.S. Group, Reduction in C-reactive protein and LDL cholesterol and cardiovascular event rates after initiation of rosuvastatin: a prospective study of the JUPITER trial, Lancet 373(9670) (2009) 1175-82.

[50] C.B. Newman, D. Preiss, J.A. Tobert, T.A. Jacobson, R.L. Page, 2nd, L.B. Goldstein, C. Chin, L.R. Tannock, M. Miller, G. Raghuveer, P.B. Duell, E.A. Brinton, A. Pollak, L.T. Braun, F.K. Welty, L.M. American Heart Association Clinical Lipidology, a.J.C.o.t.C.o.A.T. Thrombosis Committee, B. Vascular, L. Council on, H. Cardiometabolic, Y. Council on Cardiovascular Disease in the, C. Council on Clinical, C. Stroke, Statin Safety and Associated Adverse Events: A Scientific Statement From the American Heart Association, Arterioscler Thromb Vasc Biol 39(2) (2019) e38-e81.

[51] M.A. Pfeffer, F.M. Sacks, L.A. Moye, L. Brown, J.L. Rouleau, L.H. Hartley, J. Rouleau, R. Grimm, F. Sestier, W. Wickemeyer, et al., Cholesterol and Recurrent Events: a secondary prevention trial for normolipidemic patients. CARE Investigators, Am J Cardiol 76(9) (1995) 98C-106C.

[52] R.J. Simes, I.C. Marschner, D. Hunt, D. Colquhoun, D. Sullivan, R.A. Stewart, W. Hague, A. Keech, P. Thompson, H. White, J. Shaw, A. Tonkin, L.S. Investigators, Relationship between lipid levels and clinical outcomes in the Long-term Intervention with Pravastatin in Ischemic Disease (LIPID) Trial: to what extent is the reduction in coronary events with pravastatin explained by onstudy lipid levels?, Circulation 105(10) (2002) 1162-9.

[53] R. Collins, J. Armitage, S. Parish, P. Sleight, R. Peto, G. Heart Protection Study Collaborative, Effects of cholesterol-lowering with simvastatin on stroke and other major vascular events in 20536 people with cerebrovascular disease or other high-risk conditions, Lancet 363(9411) (2004) 757-67. 
[54] P. Amarenco, J. Bogousslavsky, A. Callahan, 3rd, L.B. Goldstein, M. Hennerici, A.E. Rudolph, H. Sillesen, L. Simunovic, M. Szarek, K.M. Welch, J.A. Zivin, I. Stroke Prevention by Aggressive Reduction in Cholesterol Levels, High-dose atorvastatin after stroke or transient ischemic attack, N Engl J Med 355(6) (2006) 549-59.

[55] J.S. Kim, Role of Blood Lipid Levels and Lipid-Lowering Therapy in Stroke Patients with Different Levels of Cerebral Artery Diseases: Reconsidering Recent Stroke Guidelines, J Stroke 23(2) (2021) 149-161.

[56] K.I. Paraskevas, A.A. Tzovaras, D.D. Briana, D.P. Mikhailidis, Emerging indications for statins: a pluripotent family of agents with several potential applications, Curr Pharm Des 13(35) (2007) 3622-36.

[57] K.I. Paraskevas, F.J. Veith, H.H. Eckstein, J.B. Ricco, D.P. Mikhailidis, Cholesterol, carotid artery disease and stroke: what the vascular specialist needs to know, Ann Transl Med 8(19) (2020) 1265.

[58] M. Jasińska, J. Owczarek, D. Orszulak-Michalak, Statins: a new insight into their mechanisms of action and consequent pleiotropic effects, Pharmacol Rep 59(5) (2007) 483-99.

[59] O. Bedi, V. Dhawan, P.L. Sharma, P. Kumar, Pleiotropic effects of statins: new therapeutic targets in drug design, Naunyn Schmiedebergs Arch Pharmacol 389(7) (2016) 695-712.

[60] N. Hosomi, Y. Nagai, T. Kohriyama, T. Ohtsuki, S. Aoki, T. Nezu, H. Maruyama, N. Sunami, C. Yokota, K. Kitagawa, Y. Terayama, M. Takagi, S. Ibayashi, M. Nakamura, H. Origasa, M. Fukushima, E. Mori, K. Minematsu, S. Uchiyama, Y. Shinohara, T. Yamaguchi, M. Matsumoto, J.S. Collaborators, The Japan Statin Treatment Against Recurrent Stroke (J-STARS): A Multicenter, Randomized, Open-label, Parallel-group Study, EBioMedicine 2(9) (2015) 1071-8.

[61] A.C. Flint, H. Kamel, B.B. Navi, V.A. Rao, B.S. Faigeles, C. Conell, J.G. Klingman, S. Sidney, N.K. Hills, M. Sorel, S.P. Cullen, S.C. Johnston, Statin use during ischemic stroke hospitalization is strongly associated with improved poststroke survival, Stroke 43(1) (2012) 147-54.

[62] S. Yoshimura, K. Uchida, T. Daimon, R. Takashima, K. Kimura, T. Morimoto, A.T. Investigator, Randomized Controlled Trial of Early Versus Delayed Statin Therapy in Patients With Acute Ischemic Stroke: ASSORT Trial (Administration of Statin on Acute Ischemic Stroke Patient), Stroke 48(11) (2017) 3057-3063.

[63] Y. Guo, X. Guo, K. Zhao, Q. Bao, J. Yang, M. Yang, Statin Use and Outcomes of Patients With Acute Ischemic Stroke Treated With Intravenous Thrombolysis: A Systematic Review and Meta-Analysis, Front Neurol 12 (2021) 734927.

[64] X. Li, F. Gu, J. Ding, J. Bian, N. Wang, R. Shu, Q. Li, X. Xu, The predictors and prognosis for unexpected reocclusion after mechanical thrombectomy: a meta-analysis, Ann Transl Med 8(23) (2020) 1566.

[65] J.P. Marto, D. Strambo, S.D. Hajdu, A. Eskandari, S. Nannoni, G. Sirimarco, B. Bartolini, F. Puccinelli, P. Maeder, G. Saliou, P. Michel, Twenty-Four-Hour Reocclusion After Successful Mechanical Thrombectomy: Associated Factors and Long-Term Prognosis, Stroke 50(10) (2019) 2960-2963.

[66] S.H. Lee, H.S. Shin, I. Oh, The Protective Effects of Statins Towards Vessel Wall Injury Caused by a Stent Retrieving Mechanical Thrombectomy Device : A Histological Analysis of the Rabbit Carotid Artery Model, J Korean Neurosurg Soc 64(5) (2021) 693-704.

[67] A.H. Katsanos, V.A. Lioutas, A. Charidimou, L. Catanese, K.K.H. Ng, K. Perera, D. de Sa Boasquevisque, G. Tsivgoulis, E.E. Smith, M. Sharma, M.H. Selim, A. Shoamanesh, Statin treatment and accrual of covert cerebral ischaemia on neuroimaging: a systematic review and meta-analysis of randomized trials, Eur J Neurol 27(6) (2020) 1023-1027.

[68] D. Lu, L. Shen, H. Mai, J. Zang, Y. Liu, C.K. Tsang, K. Li, A. Xu, HMG-CoA Reductase Inhibitors Attenuate Neuronal Damage by Suppressing Oxygen Glucose Deprivation-Induced Activated Microglial Cells, Neural Plast 2019 (2019) 7675496.

[69] T. Zhang, D. Lu, W. Yang, C. Shi, J. Zang, L. Shen, H. Mai, A. Xu, HMG-CoA Reductase Inhibitors Relieve Endoplasmic Reticulum Stress by Autophagy Inhibition in Rats With Permanent Brain Ischemia, Front Neurosci 12 (2018) 405.

[70] Z.J. Cheng, T.M. Dai, Y.Y. Shen, J.L. He, J. Li, J.L. Tu, Atorvastatin Pretreatment Attenuates Ischemic Brain Edema by Suppressing Aquaporin 4, J Stroke Cerebrovasc Dis 27(11) (2018) 3247-3255.

[71] S. Matsubara, T. Tanaka, S. Tomari, K. Fukuma, H. Ishiyama, S. Abe, T. Arimizu, Y. Yamaguchi, S. Ogata, K. Nishimura, M. Koga, Y. Ando, K. Toyoda, M. Ihara, Statin treatment can reduce incidence of early seizure in acute ischemic stroke: A propensity score analysis, Sci Rep 10(1) (2020) 1968.

[72] T. Zhao, Y. Ding, X. Feng, C. Zhou, W. Lin, Effects of atorvastatin and aspirin on post-stroke epilepsy and usage of levetiracetam, Medicine (Baltimore) 99(50) (2020) e23577.

[73] Y. Li, B. Zhang, L. Zhang, D. Xie, Y. Li, Efficacy of Statin therapy in post-stroke seizure prophylaxis: Clues from an observational study of routine secondary prevention treatment, Seizure 71 (2019) 185-189.

[74] D.G. Hackam, M. Woodward, L.K. Newby, D.L. Bhatt, M. Shao, E.E. Smith, A. Donner, M. Mamdani, J.D. Douketis, H. Arima, J. Chalmers, S. MacMahon, D.L. Tirschwell, B.M. Psaty, C.D. Bushnell, M.I. Aguilar, D.J. Capampangan, D.J. Werring, P. De Rango, A. Viswanathan, N. Danchin, C.L. Cheng, Y.H. Yang, B.M. Verdel, M.S. Lai, J. Kennedy, S. Uchiyama, T. Yamaguchi, Y. Ikeda, M. Mrkobrada, Statins and intracerebral hemorrhage: collaborative systematic review and meta-analysis, Circulation 124(20) (2011) 2233-42.

[75] J. Gutierrez, Is the Benefit of Antithrombotics and Statins Worth the Risk of Intracerebral Hemorrhage?: It Depends, J Am Heart Assoc 10(5) (2021) e020460.

[76] A.H. Katsanos, V.A. Lioutas, A. Charidimou, L. Catanese, K.K.H. Ng, K. Perera, D. de Sa Boasquevisque, G.J. Falcone, K.N. Sheth, J.R. Romero, G. Tsivgoulis, E.E. Smith, M. Sharma, M.H. Selim, A. Shoamanesh, M.-M.I. International, Statin treatment and cerebral microbleeds: A systematic review and meta-analysis, J Neurol Sci 420 (2021) 117224. 
[77] W. Saliba, H.S. Rennert, O. Barnett-Griness, N. Gronich, J. Molad, G. Rennert, E. Auriel, Association of statin use with spontaneous intracerebral hemorrhage: A cohort study, Neurology 91(5) (2018) e400-e409.

[78] D. Yang, R.A. Knight, Y. Han, K. Karki, J. Zhang, M. Chopp, D.M. Seyfried, Statins Protect the Blood Brain Barrier Acutely after Experimental Intracerebral Hemorrhage, J Behav Brain Sci 3(1) (2013) 100-106.

[79] J.J. Cui, D. Wang, F. Gao, Y.R. Li, Effects of atorvastatin on pathological changes in brain tissue and plasma MMP-9 in rats with intracerebral hemorrhage, Cell Biochem Biophys 62(1) (2012) 87-90.

[80] T. Ewen, L. Qiuting, T. Chaogang, T. Tao, W. Jun, T. Liming, X. Guanghong, Neuroprotective effect of atorvastatin involves suppression of TNF- $\alpha$ and upregulation of IL-10 in a rat model of intracerebral hemorrhage, Cell Biochem Biophys 66(2) (2013) 33746.

[81] C.J. Chen, D. Ding, N. Ironside, T.J. Buell, L.J. Elder, A. Warren, A.P. Adams, S.J. Ratcliffe, R.F. James, N.S. Naval, B.B. Worrall, K.C. Johnston, A.M. Southerland, Statins for neuroprotection in spontaneous intracerebral hemorrhage, Neurology 93(24) (2019) 1056-1066.

[82] L. Zi, W. Zhou, J. Xu, J. Li, N. Li, J. Xu, C. You, C. Wang, M. Tian, Rosuvastatin Nanomicelles Target Neuroinflammation and Improve Neurological Deficit in a Mouse Model of Intracerebral Hemorrhage, Int J Nanomedicine 16 (2021) $2933-2947$.

[83] W. Qi, D. Cao, Y. Li, A. Peng, Y. Wang, K. Gao, C. Tao, Y. Wu, Atorvastatin ameliorates early brain injury through inhibition of apoptosis and ER stress in a rat model of subarachnoid hemorrhage, Biosci Rep 38(3) (2018).

[84] J.H. Chen, T. Wu, L.K. Yang, L. Chen, J. Zhu, P.P. Li, X. Hu, Y.H. Wang, Protective effects of atorvastatin on cerebral vessel autoregulation in an experimental rabbit model of subarachnoid hemorrhage, Mol Med Rep 17(1) (2018) 1651-1659.

[85] J.H. Chen, L.K. Yang, L. Chen, Y.H. Wang, Y. Wu, B.J. Jiang, J. Zhu, P.P. Li, Atorvastatin ameliorates early brain injury after subarachnoid hemorrhage via inhibition of AQP4 expression in rabbits, Int J Mol Med 37(4) (2016) 1059-66.

[86] J. Chen, M. Li, X. Zhu, L. Chen, S. Yang, C. Zhang, T. Wu, X. Feng, Y. Wang, Q. Chen, Atorvastatin reduces cerebral vaso spasm and infarction after aneurysmal subarachnoid hemorrhage in elderly Chinese adults, Aging (Albany NY) 12(3) (2020) $2939-2951$.

[87] T.J. Song, S.H. Oh, J. Kim, The impact of statin therapy after surgical or endovascular treatment of cerebral aneurysms, J Neurosurg (2019) 1-8.

[88] M. Naraoka, N. Matsuda, N. Shimamura, K. Asano, K. Akasaka, A. Takemura, S. Hasegawa, H. Ohkuma, Long-acting statin for aneurysmal subarachnoid hemorrhage: A randomized, double-blind, placebo-controlled trial, J Cereb Blood Flow Metab 38(7) (2018) 1190-1198.

[89] J.R. Lynch, H. Wang, M.J. McGirt, J. Floyd, A.H. Friedman, A.L. Coon, R. Blessing, M.J. Alexander, C. Graffagnino, D.S. Warner, D.T. Laskowitz, Simvastatin reduces vasospasm after aneurysmal subarachnoid hemorrhage: results of a pilot randomized clinical trial, Stroke 36(9) (2005) 2024-6.

[90] S.H. Su, W. Xu, J. Hai, Y.F. Wu, F. Yu, Effects of statins-use for patients with aneurysmal subarachnoid hemorrhage: a metaanalysis of randomized controlled trials, Sci Rep 4 (2014) 4573.

[91] J. Shen, J. Shen, K. Zhu, H. Zhou, H. Tian, G. Yu, Efficacy of Statins in Cerebral Vasospasm, Mortality, and Delayed Cerebral Ischemia in Patients with Aneurysmal Subarachnoid Hemorrhage: A Systematic Review and Meta-Analysis of Randomized Controlled Trials, World Neurosurg 131 (2019) e65-e73.

[92] S. Bohara, V.B. Gaonkar, K. Garg, P.M.S. Rajpal, P.K. Singh, M. Singh, A. Suri, P.S. Chandra, S.S. Kale, Effect of statins on functional outcome and mortality following aneurysmal subarachnoid hemorrhage - Results of a meta-analysis, metaregression and trial sequential analysis, Clin Neurol Neurosurg 207 (2021) 106787.

[93] M.D. Vergouwen, J.C. Meijers, R.B. Geskus, B.A. Coert, J. Horn, E.S. Stroes, T. van der Poll, M. Vermeulen, Y.B. Roos, Biologic effects of simvastatin in patients with aneurysmal subarachnoid hemorrhage: a double-blind, placebo-controlled randomized trial, $\mathrm{J}$ Cereb Blood Flow Metab 29(8) (2009) 1444-53.

[94] J. Lin, H. Liu, J. Jiang, C. Jia, B. Zhang, X. Gao, Clinical evidence of efficacy of simvastatin for aneurysmal subarachnoid hemorrhage, J Int Med Res 45(6) (2017) 2128-2138.

[95] A. Can, V.M. Castro, D. Dligach, S. Finan, S. Yu, V. Gainer, N.A. Shadick, G. Savova, S. Murphy, T. Cai, S.T. Weiss, R. Du, LipidLowering Agents and High HDL (High-Density Lipoprotein) Are Inversely Associated With Intracranial Aneurysm Rupture, Stroke 49(5) (2018) 1148-1154.

[96] M. Terceno, S. Remollo, Y. Silva, S. Bashir, M. Werner, V.A. Vera-Monge, J. Serena, C. Castano, Effect of combined acetylsalicylic acid and statins treatment on intracranial aneurysm rupture, PLoS One 16(2) (2021) e0247153.

[97] K. Yoshida, I. Uwano, M. Sasaki, O. Takahashi, N. Sakai, W. Tsuruta, H. Nakase, K. Ogasawara, T. Osato, J.C. Takahashi, T. Hatano, H. Kinouchi, S. Miyamoto, S.U.-P.t. Investigators, Small Unruptured Aneurysm Verification-prevention Effect against Growth of Cerebral Aneurysm Study Using Statin, Neurol Med Chir (Tokyo) 61(7) (2021) 442-451.

[98] J. Longo, J.E. van Leeuwen, M. Elbaz, E. Branchard, L.Z. Penn, Statins as Anticancer Agents in the Era of Precision Medicine, Clin Cancer Res 26(22) (2020) 5791-5800.

[99] S. Borgquist, O. Bjarnadottir, S. Kimbung, T.P. Ahern, Statins: a role in breast cancer therapy?, J Intern Med 284(4) (2018) 346357.

[100] B. Guerra, C. Recio, H. Aranda-Tavio, M. Guerra-Rodriguez, J.M. Garcia-Castellano, L. Fernandez-Perez, The Mevalonate Pathway, a Metabolic Target in Cancer Therapy, Front Oncol 11 (2021) 626971. 
[101] N. Germain, M. Dhayer, M. Boileau, Q. Fovez, J. Kluza, P. Marchetti, Lipid Metabolism and Resistance to Anticancer Treatment, Biology (Basel) 9(12) (2020).

[102] W. Jiang, J.W. Hu, X.R. He, W.L. Jin, X.Y. He, Statins: a repurposed drug to fight cancer, J Exp Clin Cancer Res 40(1) (2021) 241. [103] L.J. Martin, O. Melnichouk, E. Huszti, P.W. Connelly, C.V. Greenberg, S. Minkin, N.F. Boyd, Serum lipids, lipoproteins, and risk of breast cancer: a nested case-control study using multiple time points, J Natl Cancer Inst 107(5) (2015).

[104] K. Undela, V. Srikanth, D. Bansal, Statin use and risk of breast cancer: a meta-analysis of observational studies, Breast Cancer Res Treat 135(1) (2012) 261-9.

[105] U.C. Mc Menamin, L.J. Murray, C.M. Hughes, C.R. Cardwell, Statin use and breast cancer survival: a nationwide cohort study in Scotland, BMC Cancer 16 (2016) 600.

[106] S. Borgquist, P. Broberg, J. Tojjar, H. Olsson, Statin use and breast cancer survival - a Swedish nationwide study, BMC Cancer 19(1) (2019) 54.

[107] M.K. Nowakowska, X. Lei, M.T. Thompson, S.F. Shaitelman, M.R. Wehner, W.A. Woodward, S.H. Giordano, K.T. Nead, Association of statin use with clinical outcomes in patients with triple-negative breast cancer, Cancer (2021).

[108] C.A. Goard, M. Chan-Seng-Yue, P.J. Mullen, A.D. Quiroga, A.R. Wasylishen, J.W. Clendening, D.H. Sendorek, S. Haider, R. Lehner, P.C. Boutros, L.Z. Penn, Identifying molecular features that distinguish fluvastatin-sensitive breast tumor cells, Breast Cancer Res Treat 143(2) (2014) 301-12.

[109] K. Warita, T. Warita, C.H. Beckwitt, M.E. Schurdak, A. Vazquez, A. Wells, Z.N. Oltvai, Statin-induced mevalonate pathway inhibition attenuates the growth of mesenchymal-like cancer cells that lack functional E-cadherin mediated cell cohesion, Sci Rep 4 (2014) 7593.

[110] V.S. Viswanathan, M.J. Ryan, H.D. Dhruv, S. Gill, O.M. Eichhoff, B. Seashore-Ludlow, S.D. Kaffenberger, J.K. Eaton, K. Shimada, A.J. Aguirre, S.R. Viswanathan, S. Chattopadhyay, P. Tamayo, W.S. Yang, M.G. Rees, S. Chen, Z.V. Boskovic, S. Javaid, C. Huang, X. Wu, Y.Y. Tseng, E.M. Roider, D. Gao, J.M. Cleary, B.M. Wolpin, J.P. Mesirov, D.A. Haber, J.A. Engelman, J.S. Boehm, J.D. Kotz, C.S. Hon, Y. Chen, W.C. Hahn, M.P. Levesque, J.G. Doench, M.E. Berens, A.F. Shamji, P.A. Clemons, B.R. Stockwell, S.L. Schreiber, Dependency of a therapy-resistant state of cancer cells on a lipid peroxidase pathway, Nature 547(7664) (2017) 453-457.

[111] R. Yu, J. Longo, J.E. van Leeuwen, P.J. Mullen, W. Ba-Alawi, B. Haibe-Kains, L.Z. Penn, Statin-Induced Cancer Cell Death Can Be Mechanistically Uncoupled from Prenylation of RAS Family Proteins, Cancer Res 78(5) (2018) 1347-1357.

[112] E.R. Garwood, A.S. Kumar, F.L. Baehner, D.H. Moore, A. Au, N. Hylton, C.I. Flowers, J. Garber, B.A. Lesnikoski, E.S. Hw ang, O. Olopade, E.R. Port, M. Campbell, L.J. Esserman, Fluvastatin reduces proliferation and increases apoptosis in women with high grade breast cancer, Breast Cancer Res Treat 119(1) (2010) 137-44.

[113] M. Feldt, O. Bjarnadottir, S. Kimbung, K. Jirstrom, P.O. Bendahl, S. Veerla, D. Grabau, I. Hedenfalk, S. Borgquist, Statin-induced anti-proliferative effects via cyclin D1 and p27 in a window-of-opportunity breast cancer trial, J Transl Med 13 (2015) 133.

[114] H. Alarfi, L.A. Youssef, M. Salamoon, A Prospective, Randomized, Placebo-Controlled Study of a Combination of Simvastatin and Chemotherapy in Metastatic Breast Cancer, J Oncol 2020 (2020) 4174395.

[115] E.D. Yulian, N.C. Siregar, Bajuadji, Combination of Simvastatin and FAC Improves Response to Neoadjuvant Chemotherapy in Advanced Local Breast Cancer, Cancer Res Treat (2021).

[116] A. Ghasemi, Z. Ghashghai, J. Akbari, J. Yazdani-Charati, E. Salehifar, S.J. Hosseinimehr, Topical atorvastatin 1\% for prevention of skin toxicity in patients receiving radiation therapy for breast cancer: a randomized, double-blind, placebo-controlled trial, Eur J Clin Pharmacol 75(2) (2019) 171-178.

[117] M. Nabati, G. Janbabai, J. Esmailian, J. Yazdani, Effect of Rosuvastatin in Preventing Chemotherapy-Induced Cardiotoxicity in Women With Breast Cancer: A Randomized, Single-Blind, Placebo-Controlled Trial, J Cardiovasc Pharmacol Ther 24(3) (2019) 233241.

[118] O. Calvillo-Arguelles, H. Abdel-Qadir, M. Michalowska, F. Billia, S. Suntheralingam, E. Amir, P. Thavendiranathan, Cardioprotective Effect of Statins in Patients With HER2-Positive Breast Cancer Receiving Trastuzumab Therapy, Can J Cardiol 35(2) (2019) 153-159.

[119] D. Pradelli, D. Soranna, A. Zambon, A. Catapano, G. Mancia, C. La Vecchia, G. Corrao, Statins use and the risk of all and subtype hematological malignancies: a meta-analysis of observational studies, Cancer Med 4(5) (2015) 770-80.

[120] S.M. Kornblau, D.E. Banker, D. Stirewalt, D. Shen, E. Lemker, S. Verstovsek, Z. Estrov, S. Faderl, J. Cortes, M. Beran, C.E. Jackson, W. Chen, E. Estey, F.R. Appelbaum, Blockade of adaptive defensive changes in cholesterol uptake and synthesis in AML by the addition of pravastatin to idarubicin + high-dose Ara-C: a phase 1 study, Blood 109(7) (2007) 2999-3006.

[121] A.S. Advani, S. McDonough, E. Copelan, C. Willman, D.A. Mulford, A.F. List, M.A. Sekeres, M. Othus, F.R. Appelbaum, SWOG0919: a Phase 2 study of idarubicin and cytarabine in combination with pravastatin for relapsed acute myeloid leukaemia, Br J Haematol 167(2) (2014) 233-7.

[122] A.S. Advani, H. Li, L.C. Michaelis, B.C. Medeiros, M. Liedtke, A.F. List, K. O'Dwyer, M. Othus, H.P. Erba, F.R. Appelbaum, Report of the relapsed/refractory cohort of SWOG S0919: A phase 2 study of idarubicin and cytarabine in combination with pravastatin for acute myelogenous leukemia (AML), Leuk Res 67 (2018) 17-20.

[123] B. Ponvilawan, N. Charoenngam, T. Rittiphairoj, P. Ungprasert, Receipt of Statins Is Associated With Lower Risk of Multiple Myeloma: Systematic Review and Meta-analysis, Clin Lymphoma Myeloma Leuk 20(7) (2020) e399-e413. 
[124] P. Zhang, B. Liu, Statin use and the risk of multiple myeloma: a PRISMA-compliant meta-analysis, Ann Hematol 99(8) (2020) 1805-1812.

[125] R. Schmidmaier, P. Baumann, I. Bumeder, G. Meinhardt, C. Straka, B. Emmerich, First clinical experience with simvastatin to overcome drug resistance in refractory multiple myeloma, Eur J Haematol 79(3) (2007) 240-3.

[126] M. Hus, N. Grzasko, M. Szostek, A. Pluta, G. Helbig, D. Woszczyk, M. Adamczyk-Cioch, D. Jawniak, W. Legiec, M. Morawska, J. Kozinska, P. Wacinski, A. Dmoszynska, Thalidomide, dexamethasone and lovastatin with autologous stem cell transplantation as a salvage immunomodulatory therapy in patients with relapsed and refractory multiple myeloma, Ann Hematol 90(10) (2011) 11616.

[127] S. Singh, A.G. Singh, P.P. Singh, M.H. Murad, P.G. Iyer, Statins are associated with reduced risk of esophageal cancer, particularly in patients with Barrett's esophagus: a systematic review and meta-analysis, Clin Gastroenterol Hepatol 11(6) (2013) 620-9.

[128] A. Fatehi Hassanabad, J.V.S. Wong, Statins as Potential Therapeutics for Esophageal Cancer, J Gastrointest Cancer 52(3) (2021) 833-838.

[129] L. Alexandre, A.B. Clark, S. Walton, M.P. Lewis, B. Kumar, E.C. Cheong, H. Warren, S.S. Kadirkamanathan, S.L. Parsons, S.M. Dresner, E. Sims, M. Jones, M. Hammond, M. Flather, Y.K. Loke, A.M. Swart, A.R. Hart, Adjuvant statin therapy for oesophageal adenocarcinoma: the STAT-ROC feasibility study, BJS Open 4(1) (2020) 59-70.

[130] M. Shyamsundar, D.F. McAuley, M.O. Shields, R. MacSweeney, M.J. Duffy, J.R. Johnston, J. McGuigan, J.T. Backman, C.S. Calfee, M.M. Matthay, M.J. Griffiths, C. McDowell, S.J. Elborn, C.M. O'Kane, Effect of simvastatin on physiological and biological outcomes in patients undergoing esophagectomy: a randomized placebo-controlled trial, Ann Surg 259(1) (2014) 26-31.

[131] H.F. Chiu, S.C. Ho, C.C. Chang, T.N. Wu, C.Y. Yang, Statins are associated with a reduced risk of gastric cancer: a populationbased case-control study, Am J Gastroenterol 106(12) (2011) 2098-103.

[132] P.P. Singh, S. Singh, Statins are associated with reduced risk of gastric cancer: a systematic review and meta-analysis, Ann Oncol 24(7) (2013) 1721-1730.

[133] X.D. Wu, K. Zeng, F.Q. Xue, J.H. Chen, Y.Q. Chen, Statins are associated with reduced risk of gastric cancer: a meta-analysis, Eur J Clin Pharmacol 69(10) (2013) 1855-60.

[134] K.S. Cheung, E.W. Chan, A.Y.S. Wong, L. Chen, W.K. Seto, I.C.K. Wong, W.K. Leung, Statins Were Associated with a Reduced Gastric Cancer Risk in Patients with Eradicated Helicobacter Pylori Infection: A Territory-Wide Propensity Score Matched Study, Cancer Epidemiol Biomarkers Prev 29(2) (2020) 493-499.

[135] W.S. Kim, M.M. Kim, H.J. Choi, S.S. Yoon, M.H. Lee, K. Park, C.H. Park, W.K. Kang, Phase II study of high-dose lovastatin in patients with advanced gastric adenocarcinoma, Invest New Drugs 19(1) (2001) 81-3.

[136] I.R. Konings, A. van der Gaast, L.J. van der Wijk, F.E. de Jongh, F.A. Eskens, S. Sleijfer, The addition of pravastatin to chemotherapy in advanced gastric carcinoma: a randomised phase II trial, Eur J Cancer 46(18) (2010) 3200-4.

[137] S.T. Kim, J.H. Kang, J. Lee, S.H. Park, J.O. Park, Y.S. Park, H.Y. Lim, I.G. Hwang, S.C. Lee, K.W. Park, H.R. Lee, W.K. Kang, Simvastatin plus capecitabine-cisplatin versus placebo plus capecitabine-cisplatin in patients with previously untreated advanced gastric cancer: a double-blind randomised phase 3 study, Eur J Cancer 50(16) (2014) 2822-30.

[138] W. Nseir, H. Diab, M. Mahamid, O. Abu-Elheja, M. Samara, A. Abid, J. Mograbi, Randomised clinical trial: simvastatin as adjuvant therapy improves significantly the Helicobacter pylori eradication rate--a placebo-controlled study, Aliment Pharmacol Ther 36(3) (2012) 231-8.

[139] S.S. Sarkeshikian, M.R. Ghadir, F. Alemi, S.M. Jalali, A. Hormati, A. Mohammadbeigi, Atorvastatin in combination with conventional antimicrobial treatment of Helicobacter pylori eradication: A randomized controlled clinical trial, J Gastroenterol Hepatol 35(1) (2020) 71-75.

[140] J.N. Poynter, S.B. Gruber, P.D. Higgins, R. Almog, J.D. Bonner, H.S. Rennert, M. Low, J.K. Greenson, G. Rennert, Statins and the risk of colorectal cancer, N Engl J Med 352(21) (2005) 2184-92.

[141] Y. Liu, W. Tang, J. Wang, L. Xie, T. Li, Y. He, Y. Deng, Q. Peng, S. Li, X. Qin, Association between statin use and colorectal cancer risk: a meta-analysis of 42 studies, Cancer Causes Control 25(2) (2014) 237-49.

[142] A. Pourlotfi, R. Ahl, G. Sjolin, M.P. Forssten, G.A. Bass, Y. Cao, P. Matthiessen, S. Mohseni, Statin therapy and postoperative short-term mortality after rectal cancer surgery, Colorectal Dis 23(4) (2021) 875-881.

[143] L.L. Krens, L.H. Simkens, J.M. Baas, E.R. Koomen, H. Gelderblom, C.J. Punt, H.J. Guchelaar, Statin use is not associated with improved progression free survival in cetuximab treated KRAS mutant metastatic colorectal cancer patients: results from the CAIRO2 study, PLoS One 9(11) (2014) e112201.

[144] K. Ng, S. Ogino, J.A. Meyerhardt, J.A. Chan, A.T. Chan, D. Niedzwiecki, D. Hollis, L.B. Saltz, R.J. Mayer, A.B. Benson, 3rd, P.L. Schaefer, R. Whittom, A. Hantel, R.M. Goldberg, M.M. Bertagnolli, A.P. Venook, C.S. Fuchs, Relationship between statin use and colon cancer recurrence and survival: results from CALGB 89803, J Natl Cancer Inst 103(20) (2011) 1540-51.

[145] S.H. Lim, T.W. Kim, Y.S. Hong, S.W. Han, K.H. Lee, H.J. Kang, I.G. Hwang, J.Y. Lee, H.S. Kim, S.T. Kim, J. Lee, J.O. Park, S.H. Park, Y.S. Park, H.Y. Lim, S.H. Jung, W.K. Kang, A randomised, double-blind, placebo-controlled multi-centre phase III trial of XELIRI/FOLFIRI plus simvastatin for patients with metastatic colorectal cancer, Br J Cancer 113(10) (2015) 1421-6.

[146] M.B. Jameson, K. Gormly, D. Espinoza, W. Hague, G. Asghari, G.M. Jeffery, T.J. Price, C.S. Karapetis, M. Arendse, J. Armstrong, J. Childs, F.A. Frizelle, S. Ngan, A. Stevenson, M. Oostendorp, S.P. Ackland, SPAR - a randomised, placebo-controlled phase II trial 
of simvastatin in addition to standard chemotherapy and radiation in preoperative treatment for rectal cancer: an AGITG clinical trial, BMC Cancer 19(1) (2019) 1229.

[147] B.W. Katona, J.M. Weiss, Chemoprevention of Colorectal Cancer, Gastroenterology 158(2) (2020) 368-388.

[148] D. Pradelli, D. Soranna, L. Scotti, A. Zambon, A. Catapano, G. Mancia, C. La Vecchia, G. Corrao, Statins and primary liver cancer: a meta-analysis of observational studies, Eur J Cancer Prev 22(3) (2013) 229-34.

[149] G.C. Zhong, Y. Liu, Y.Y. Ye, F.B. Hao, K. Wang, J.P. Gong, Meta-analysis of studies using statins as a reducer for primary liver cancer risk, Sci Rep 6 (2016) 26256.

[150] M. Shi, H. Zheng, B. Nie, W. Gong, X. Cui, Statin use and risk of liver cancer: an update meta-analysis, BMJ Open 4(9) (2014) e005399.

[151] J.L. Jouve, T. Lecomte, O. Bouche, E. Barbier, F. Khemissa Akouz, G. Riachi, E. Nguyen Khac, I. Ollivier-Hourmand, M. DebetteGratien, R. Faroux, A.L. Villing, J. Vergniol, J.F. Ramee, J.P. Bronowicki, J.F. Seitz, J.L. Legoux, J. Denis, S. Manfredi, J.M. Phelip, P.-. investigators/collaborators, Pravastatin combination with sorafenib does not improve survival in advanced hepatocellular carcinoma, J Hepatol 71(3) (2019) 516-522.

[152] J.F. Blanc, F. Khemissa, J.P. Bronowicki, C. Monterymard, J.M. Perarnau, V. Bourgeois, S. Obled, M.B. Abdelghani, I. MabileArchambeaud, R. Faroux, J.F. Seitz, C. Locher, H. Senellart, A.L. Villing, F. Audemar, C. Costentin, G. Deplanque, S. Manfredi, J. Edeline, P. collaborators, Phase 2 trial comparing sorafenib, pravastatin, their combination or supportive care in HCC with ChildPugh B cirrhosis, Hepatol Int 15(1) (2021) 93-104.

[153] I. Riano, L. Martin, M. Varela, T. Serrano, O. Nunez, B. Minguez, P.M. Rodrigues, M.J. Perugorria, J.M. Banales, J.I. Arenas, Efficacy and Safety of the Combination of Pravastatin and Sorafenib for the Treatment of Advanced Hepatocellular Carcinoma (ESTAHEP Clinical Trial), Cancers (Basel) 12(7) (2020).

[154] S. Kawata, E. Yamasaki, T. Nagase, Y. Inui, N. Ito, Y. Matsuda, M. Inada, S. Tamura, S. Noda, Y. Imai, Y. Matsuzawa, Effect of pravastatin on survival in patients with advanced hepatocellular carcinoma. A randomized controlled trial, Br J Cancer 84(7) (2001) 886-91.

[155] V. Khurana, A. Sheth, G. Caldito, J.S. Barkin, Statins reduce the risk of pancreatic cancer in humans: a case-control study of half a million veterans, Pancreas 34(2) (2007) 260-5.

[156] X. Cui, Y. Xie, M. Chen, J. Li, X. Liao, J. Shen, M. Shi, W. Li, H. Zheng, B. Jiang, Statin use and risk of pancreatic cancer: a metaanalysis, Cancer Causes Control 23(7) (2012) 1099-111.

[157] J.Y. Hong, E.M. Nam, J. Lee, J.O. Park, S.C. Lee, S.Y. Song, S.H. Choi, J.S. Heo, S.H. Park, H.Y. Lim, W.K. Kang, Y.S. Park, Randomized double-blinded, placebo-controlled phase II trial of simvastatin and gemcitabine in advanced pancreatic cancer patients, Cancer Chemother Pharmacol 73(1) (2014) 125-30.

[158] M. Tan, X. Song, G. Zhang, A. Peng, X. Li, M. Li, Y. Liu, C. Wang, Statins and the risk of lung cancer: a meta-analysis, PLoS One $8(2)$ (2013) e57349.

[159] J.L. Feng, X. Qin, Lipid-lowering medication use and cancer-specific survival among endometrial or lung cancer patients: an Australian nationwide cohort study, Eur J Clin Pharmacol 77(3) (2021) 399-407.

[160] P.M. Ridker, J.G. MacFadyen, T. Thuren, B.M. Everett, P. Libby, R.J. Glynn, C.T. Group, Effect of interleukin-1beta inhibition with canakinumab on incident lung cancer in patients with atherosclerosis: exploratory results from a randomised, double-blind, placebo-controlled trial, Lancet 390(10105) (2017) 1833-1842.

[161] M.S. Hung, I.C. Chen, C.P. Lee, R.J. Huang, P.C. Chen, Y.H. Tsai, Y.H. Yang, Statin improves survival in patients with EGFRTKI lung cancer: A nationwide population-based study, PLoS One 12(2) (2017) e0171137.

[162] P.A. Nguyen, C.C. Chang, C.J. Galvin, Y.C. Wang, S.Y. An, C.W. Huang, Y.H. Wang, M.H. Hsu, Y.J. Li, H.C. Yang, Statins use and its impact in EGFR-TKIs resistance to prolong the survival of lung cancer patients: A Cancer registry cohort study in Taiwan, Cancer Sci 111(8) (2020) 2965-2973.

[163] L. Cantini, F. Pecci, D.P. Hurkmans, R.A. Belderbos, A. Lanese, C. Copparoni, S. Aerts, R. Cornelissen, D.W. Dumoulin, I. Fiordoliva, S. Rinaldi, J. Aerts, R. Berardi, High-intensity statins are associated with improved clinical activity of PD-1 inhibitors in malignant pleural mesothelioma and advanced non-small cell lung cancer patients, Eur J Cancer 144 (2021) 41-48.

[164] M.J. Seckl, C.H. Ottensmeier, M. Cullen, P. Schmid, Y. Ngai, D. Muthukumar, J. Thompson, S. Harden, G. Middleton, K.M. Fife, B. Crosse, P. Taylor, S. Nash, A. Hackshaw, Multicenter, Phase III, Randomized, Double-Blind, Placebo-Controlled Trial of Pravastatin Added to First-Line Standard Chemotherapy in Small-Cell Lung Cancer (LUNGSTAR), J Clin Oncol 35(14) (2017) 1506-1514.

[165] Y. Lee, K.H. Lee, G.K. Lee, S.H. Lee, K.Y. Lim, J. Joo, Y.J. Go, J.S. Lee, J.Y. Han, Randomized Phase II Study of Afatinib Plus Simvastatin Versus Afatinib Alone in Previously Treated Patients with Advanced Nonadenocarcinomatous Non-small Cell Lung Cancer, Cancer Res Treat 49(4) (2017) 1001-1011.

[166] J.Y. Han, S.H. Lee, N.J. Yoo, L.S. Hyung, Y.J. Moon, T. Yun, H.T. Kim, J.S. Lee, A randomized phase II study of gefitinib plus simvastatin versus gefitinib alone in previously treated patients with advanced non-small cell lung cancer, Clin Cancer Res 17(6) (2011) 1553-60.

[167] X.L. Zhang, M. Liu, J. Qian, J.H. Zheng, X.P. Zhang, C.C. Guo, J. Geng, B. Peng, J.P. Che, Y. Wu, Statin use and risk of kidney cancer: a meta-analysis of observational studies and randomized trials, Br J Clin Pharmacol 77(3) (2014) 458-65.

[168] W. Liu, T.K. Choueiri, E. Cho, Statin use and the risk of renal cell carcinoma in 2 prospective US cohorts, Cancer 118(3) (2012) 797-803. 
[169] Y.C. Chou, C.H. Lin, C.S. Wong, W.Y. Chou, J.Y. Chang, C.A. Sun, Statin use and the risk of renal cell carcinoma: national cohort study, J Investig Med 68(3) (2020) 776-781.

[170] M. Boegemann, K. Schlack, M. Rink, S. Bernhardt, M. Moran, M. Hubbe, L. Bergmann, M. Schmid, A. Strauss, Effect of comorbidities/comedications on sunitinib outcomes for metastatic renal cell carcinoma: the STAR-TOR registry, Future Oncol 16(35) (2020) 2939-2948.

[171] A. Cortellini, M. Tucci, V. Adamo, L.S. Stucci, A. Russo, E.T. Tanda, F. Spagnolo, F. Rastelli, R. Bisonni, D. Santini, M. Russano, C. Anesi, R. Giusti, M. Filetti, P. Marchetti, A. Botticelli, A. Gelibter, M.A. Occhipinti, R. Marconcini, M.G. Vitale, L. Nicolardi, R. Chiari, C. Bareggi, O. Nigro, A. Tuzi, M. De Tursi, N. Petragnani, L. Pala, S. Bracarda, S. Macrini, A. Inno, F. Zoratto, E. Veltri, B. Di Cocco, D. Mallardo, M.G. Vitale, D.J. Pinato, G. Porzio, C. Ficorella, P.A. Ascierto, Integrated analysis of concomitant medications and oncological outcomes from PD-1/PD-L1 checkpoint inhibitors in clinical practice, J Immunother Cancer 8(2) (2020).

[172] S.K. Choi, G.E. Min, S.H. Jeon, H.L. Lee, S.G. Chang, K.H. Yoo, Effects of statins on the prognosis of local and locally advanced renal cell carcinoma following nephrectomy, Mol Clin Oncol 1(2) (2013) 365-368.

[173] R.J. Hamilton, D. Morilla, F. Cabrera, M. Leapman, L.Y. Chen, M. Bernstein, A.A. Hakimi, V.E. Reuter, P. Russo, The association between statin medication and progression after surgery for localized renal cell carcinoma, J Urol 191(4) (2014) 914-9.

[174] Y. Zhang, T. Zang, Association between statin usage and prostate cancer prevention: a refined meta-analysis based on literature from the years 2005-2010, Urol Int 90(3) (2013) 259-62.

[175] E. Lundberg, O. Hagberg, S. Jahnson, B. Ljungberg, Association between occurrence of urinary bladder cancer and treatment with statin medication, Turk J Urol 45(2) (2019) 97-102.

[176] P.O. Richard, A.E. Ahmad, S. Bashir, R.J. Hamilton, R.K. Nam, R. Leao, C. Jeldres, G.S. Kulkarni, Effect of statins as a secondary chemopreventive agent among individuals with non-muscle-invasive bladder cancer: A population-based analysis, Urol Oncol 35(6) (2017) 342-348.

[177] V. Guercio, F. Turati, C. Bosetti, J. Polesel, D. Serraino, M. Montella, M. Libra, A. Galfano, C. La Vecchia, A. Tavani, Bladder cancer risk in users of selected drugs for cardiovascular disease prevention, Eur J Cancer Prev 28(2) (2019) 76-80.

[178] K.N. Sourbeer, L.E. Howard, G.L. Andriole, D.M. Moreira, R. Castro-Santamaria, S.J. Freedland, A.C. Vidal, Metabolic syndrome-like components and prostate cancer risk: results from the Reduction by Dutasteride of Prostate Cancer Events (REDUCE) study, BJU Int 115(5) (2015) 736-43.

[179] T. Feng, L.E. Howard, A.C. Vidal, D.M. Moreira, R. Castro-Santamaria, G.L. Andriole, S.J. Freedland, Serum cholesterol and risk of lower urinary tract symptoms progression: Results from the Reduction by Dutasteride of Prostate Cancer Events study, Int J Urol 24(2) (2017) 151-156.

[180] C.H. Pernar, E.M. Ebot, K.M. Wilson, L.A. Mucci, The Epidemiology of Prostate Cancer, Cold Spring Harb Perspect Med 8(12) (2018).

[181] D. Bansal, K. Undela, S. D'Cruz, F. Schifano, Statin use and risk of prostate cancer: a meta-analysis of observational studies, PLoS One 7(10) (2012) e46691.

[182] N. Prabhu, N. Kapur, W. Catalona, R. Leikin, I. Helenowski, B. Jovanovich, M. Gurley, T.M. Okwuosa, T.M. Kuzel, Statin use and risk of prostate cancer biochemical recurrence after radical prostatectomy, Urol Oncol 39(2) (2021) 130 e9-130 e15.

[183] M.A. Moyad, G.S. Merrick, W.M. Butler, K.E. Wallner, R.W. Galbreath, B. Kurko, E. Adamovich, Statins, especially atorvastatin, may favorably influence clinical presentation and biochemical progression-free survival after brachytherapy for clinically localized prostate cancer, Urology 66(6) (2005) 1150-4.

[184] S.K. Hong, B.K. Han, S.J. Jeong, S.S. Byun, S.E. Lee, Effect of statin therapy on early return of potency after nerve sparing radical retropubic prostatectomy, J Urol 178(2) (2007) 613-6.

[185] E.H. Allott, L.E. Howard, A.C. Vidal, D.M. Moreira, R. Castro-Santamaria, G.L. Andriole, S.J. Freedland, Statin Use, Serum Lipids, and Prostate Inflammation in Men with a Negative Prostate Biopsy: Results from the REDUCE Trial, Cancer Prev Res (Phila) 10(6) (2017) 319-326.

[186] E.H. Allott, I. Csizmadi, L.E. Howard, R.L. Muller, D.M. Moreira, G.L. Andriole, C.G. Roehrborn, S.J. Freedland, Statin use and longitudinal changes in prostate volume; results from the REduction by DUtasteride of prostate Cancer Events (REDUCE) trial, BJU Int 125(2) (2020) 226-233.

[187] M.J. Roberts, J.W. Yaxley, G.D. Coughlin, T.R. Gianduzzo, R.C. Esler, N.T. Dunglison, S.K. Chambers, R.J. Medcraft, C.W. Chow, H.J. Schirra, R.S. Richards, N. Kienzle, M. Lu, I. Brereton, H. Samaratunga, J. Perry-Keene, D. Payton, C. Oyama, S.A. Doi, M.F. Lavin, R.A. Gardiner, Can atorvastatin with metformin change the natural history of prostate cancer as characterized by molecular, metabolomic, imaging and pathological variables? A randomized controlled trial protocol, Contemp Clin Trials 50 (2016) 16-20.

[188] J.R. Downs, M. Clearfield, S. Weis, E. Whitney, D.R. Shapiro, P.A. Beere, A. Langendorfer, E.A. Stein, W. Kruyer, A.M. Gotto, Jr., Primary prevention of acute coronary events with lovastatin in men and women with average cholesterol levels: results of AFCAPS/TexCAPS. Air Force/Texas Coronary Atherosclerosis Prevention Study, JAMA 279(20) (1998) 1615-22.

[189] J.L. Feng, X. Qin, Does adherence to lipid-lowering medications improve cancer survival? A nationwide study of breast and colorectal cancer, and melanoma, Br J Clin Pharmacol 87(4) (2021) 1847-1858.

[190] S.A. Johannesdottir, E.T. Chang, F. Mehnert, M. Schmidt, A.B. Olesen, H.T. Sorensen, Nonsteroidal anti-inflammatory drugs and the risk of skin cancer: a population-based case-control study, Cancer 118(19) (2012) 4768-76. 
[191] S.R. Freeman, A.L. Drake, L.F. Heilig, M. Graber, K. McNealy, L.M. Schilling, R.P. Dellavalle, Statins, fibrates, and melanoma risk: a systematic review and meta-analysis, J Natl Cancer Inst 98(21) (2006) 1538-46.

[192] K.G. Linden, S.A. Leachman, J.S. Zager, J.G. Jakowatz, J.L. Viner, C.E. McLaren, R.J. Barr, P.M. Carpenter, W.P. Chen, C.A. Elmets, J.A. Tangrea, S.J. Lim, A.J. Cochran, F.L. Meyskens, Jr., A randomized, double-blind, placebo-controlled phase II clinical trial of lovastatin for various endpoints of melanoma pathobiology, Cancer Prev Res (Phila) 7(5) (2014) 496-504.

[193] L. Emilsson, X. Garcia-Albeniz, R.W. Logan, E.C. Caniglia, M. Kalager, M.A. Hernan, Examining Bias in Studies of Statin Treatment and Survival in Patients With Cancer, JAMA Oncol 4(1) (2018) 63-70.

[194] K. Yadav, R.J. Lewis, Immortal Time Bias in Observational Studies, JAMA 325(7) (2021) 686-687.

[195] K.M. Anderson, W.P. Castelli, D. Levy, Cholesterol and mortality. 30 years of follow-up from the Framingham study, JAMA 257(16) (1987) 2176-80.

[196] H. Iso, Y. Naito, A. Kitamura, S. Sato, M. Kiyama, Y. Takayama, M. Iida, T. Shimamoto, T. Sankai, Y. Komachi, Serum total cholesterol and mortality in a Japanese population, J Clin Epidemiol 47(9) (1994) 961-9.

[197] G. Wannamethee, A.G. Shaper, P.H. Whincup, M. Walker, Low serum total cholesterol concentrations and mortality in middle aged British men, BMJ 311(7002) (1995) 409-13.

[198] Y.M. Song, J. Sung, J.S. Kim, Which cholesterol level is related to the lowest mortality in a population with low mean cholesterol level: a 6.4-year follow-up study of 482,472 Korean men, Am J Epidemiol 151(8) (2000) 739-47.

[199] M. Matsuzaki, T. Kita, H. Mabuchi, Y. Matsuzawa, N. Nakaya, S. Oikawa, Y. Saito, J. Sasaki, K. Shimamoto, H. Itakura, J.L.S.G.J.L.I. Trial, Large scale cohort study of the relationship between serum cholesterol concentration and coronary events with low-dose simvastatin therapy in Japanese patients with hypercholesterolemia, Circ J 66(12) (2002) 1087-95.

[200] M. Malmborg, C.B. Christiansen, M.D. Schmiegelow, C. Torp-Pedersen, G. Gislason, M. Schou, Incidence of new onset cancer in patients with a myocardial infarction - a nationwide cohort study, BMC Cardiovasc Disord 18(1) (2018) 198.

[201] A. Pursnani, J.M. Massaro, R.B. D'Agostino, Sr., C.J. O'Donnell, U. Hoffmann, Guideline-Based Statin Eligibility, Cancer Events, and Noncardiovascular Mortality in the Framingham Heart Study, J Clin Oncol 35(25) (2017) 2927-2933.

[202] F. Zhang, L. Liu, C. Zhang, S. Ji, Z. Mei, T. Li, Association of Metabolic Syndrome and Its Components With Risk of Stroke Recurrence and Mortality: A Meta-analysis, Neurology 97(7) (2021) e695-e705.

[203] E.J. Sijbrands, R.G. Westendorp, J.C. Defesche, P.H. de Meier, A.H. Smelt, J.J. Kastelein, Mortality over two centuries in large pedigree with familial hypercholesterolaemia: family tree mortality study, BMJ 322(7293) (2001) 1019-23.

[204] R.J. Spiegel, E.J. Schaefer, I.T. Magrath, B.K. Edwards, Plasma lipid alterations in leukemia and lymphoma, Am J Med 72(5) (1982) 775-82.

[205] C.G. Alexopoulos, B. Blatsios, A. Avgerinos, Serum lipids and lipoprotein disorders in cancer patients, Cancer 60(12) (1987) 3065-70.

[206] S.J. Lewis, F.M. Sacks, J.S. Mitchell, C. East, S. Glasser, S. Kell, R. Letterer, M. Limacher, L.A. Moye, J.L. Rouleau, M.A. Pfeffer, E. Braunwald, Effect of pravastatin on cardiovascular events in women after myocardial infarction: the cholesterol and recurrent events (CARE) trial, J Am Coll Cardiol 32(1) (1998) 140-6.

[207] H. Iwata, K. Matsuo, S. Hara, K. Takeuchi, T. Aoyama, N. Murashige, Y. Kanda, S. Mori, R. Suzuki, S. Tachibana, M. Yamane, M. Odawara, Y. Mutou, M. Kami, Use of hydroxy-methyl-glutaryl coenzyme A reductase inhibitors is associated with risk of lymphoid malignancies, Cancer Sci 97(2) (2006) 133-8.

[208] I. Agalliu, C.A. Salinas, P.D. Hansten, E.A. Ostrander, J.L. Stanford, Statin use and risk of prostate cancer: results from a population-based epidemiologic study, Am J Epidemiol 168(3) (2008) 250-60.

[209] P. Hoffmann, T. Roumeguere, C. Schulman, R. van Velthoven, Use of statins and outcome of BCG treatment for bladder cancer, N Engl J Med 355(25) (2006) 2705-7.

[210] A.A. Alsheikh-Ali, T.A. Trikalinos, D.M. Kent, R.H. Karas, Statins, low-density lipoprotein cholesterol, and risk of cancer, J Am Coll Cardiol 52(14) (2008) 1141-7.

[211] I. Ford, G.J. Blauw, M.B. Murphy, J. Shepherd, S.M. Cobbe, E.L. Bollen, B.M. Buckley, J.W. Jukema, M. Hyland, A. Gaw, A.M. Lagaay, I.J. Perry, P. Macfarlane, J. Norrie, A.E. Meinders, B.J. Sweeney, C.J. Packard, R.G. Westendorp, C. Twomey, D.J. Stott, P.S.G. The, A Prospective Study of Pravastatin in the Elderly at Risk (PROSPER): Screening Experience and Baseline Characteristics, Curr Control Trials Cardiovasc Med 3(1) (2002) 8.

[212] D. Hunt, P. Young, J. Simes, W. Hague, S. Mann, D. Owensby, G. Lane, A. Tonkin, Benefits of pravastatin on cardiovascular events and mortality in older patients with coronary heart disease are equal to or exceed those seen in younger patients: Results from the LIPID trial, Ann Intern Med 134(10) (2001) 931-40.

[213] M.R. Goldstein, L. Mascitelli, F. Pezzetta, Primary prevention of cardiovascular disease with statins: cautionary notes, QJM 102(11) (2009) 817-20.

[214] M.F. Oliver, Cholesterol-lowering and cancer in the prevention of cardiovascular disease, QJM 103(3) (2010) 202.

[215] H. Nakamura, K. Arakawa, H. Itakura, A. Kitabatake, Y. Goto, T. Toyota, N. Nakaya, S. Nishimoto, M. Muranaka, A. Yamamoto, K. Mizuno, Y. Ohashi, M.S. Group, Primary prevention of cardiovascular disease with pravastatin in Japan (MEGA Study): a prospective randomised controlled trial, Lancet 368(9542) (2006) 1155-63.

[216] S. Yusuf, J. Bosch, G. Dagenais, J. Zhu, D. Xavier, L. Liu, P. Pais, P. Lopez-Jaramillo, L.A. Leiter, A. Dans, A. Avezum, L.S. Piegas, A. Parkhomenko, K. Keltai, M. Keltai, K. Sliwa, R.J. Peters, C. Held, I. Chazova, K. Yusoff, B.S. Lewis, P. Jansky, K. Khunti, W.D. Toff, 
C.M. Reid, J. Varigos, G. Sanchez-Vallejo, R. McKelvie, J. Pogue, H. Jung, P. Gao, R. Diaz, E. Lonn, H.-. Investigators, Cholesterol Lowering in Intermediate-Risk Persons without Cardiovascular Disease, N Engl J Med 374(21) (2016) 2021-31.

[217] S. Yusuf, P. Joseph, A. Dans, P. Gao, K. Teo, D. Xavier, P. Lopez-Jaramillo, K. Yusoff, A. Santoso, H. Gamra, S. Talukder, C. Christou, P. Girish, K. Yeates, F. Xavier, G. Dagenais, C. Rocha, T. McCready, J. Tyrwhitt, J. Bosch, P. Pais, I. International Polycap Study, Polypill with or without Aspirin in Persons without Cardiovascular Disease, N Engl J Med 384(3) (2021) $216-228$.

[218] T.B. Newman, S.B. Hulley, Carcinogenicity of lipid-lowering drugs, JAMA 275(1) (1996) 55-60.

[219] C.P. Cannon, M.A. Blazing, R.P. Giugliano, A. McCagg, J.A. White, P. Theroux, H. Darius, B.S. Lewis, T.O. Ophuis, J.W. Jukema, G.M. De Ferrari, W. Ruzyllo, P. De Lucca, K. Im, E.A. Bohula, C. Reist, S.D. Wiviott, A.M. Tershakovec, T.A. Musliner, E. Braunwald, R.M. Califf, I.-I. Investigators, Ezetimibe Added to Statin Therapy after Acute Coronary Syndromes, N Engl J Med 372(25) (2015) 2387-97.

[220] A.B. Rossebo, T.R. Pedersen, K. Boman, P. Brudi, J.B. Chambers, K. Egstrup, E. Gerdts, C. Gohlke-Barwolf, I. Holme, Y.A. Kesaniemi, W. Malbecq, C.A. Nienaber, S. Ray, T. Skjaerpe, K. Wachtell, R. Willenheimer, S. Investigators, Intensive lipid lowering with simvastatin and ezetimibe in aortic stenosis, N Engl J Med 359(13) (2008) 1343-56.

[221] R.P. Giugliano, B. Gencer, S.D. Wiviott, J.G. Park, C.S. Fuchs, W. Goessling, T.A. Musliner, A.M. Tershakovec, M.A. Blazing, R. Califf, C.P. Cannon, E. Braunwald, Prospective Evaluation of Malignancy in 17,708 Patients Randomized to Ezetimibe Versus Placebo: Analysis From IMPROVE-IT, JACC CardioOncol 2(3) (2020) 385-396.

[222] A. Green, D.R. Ramey, M. Emneus, M. Iachina, K. Stavem, K. Bolin, R. McNally, M. Busch-Sorensen, R. Willenheimer, K. Egstrup, Y.A. Kesaniemi, S. Ray, N. Basta, C. Kent, T.R. Pedersen, Incidence of cancer and mortality in patients from the Simva statin and Ezetimibe in Aortic Stenosis (SEAS) trial, Am J Cardiol 114(10) (2014) 1518-22.

[223] M.S. Sabatine, R.P. Giugliano, A.C. Keech, N. Honarpour, S.D. Wiviott, S.A. Murphy, J.F. Kuder, H. Wang, T. Liu, S.M. Wasserman, P.S. Sever, T.R. Pedersen, F.S. Committee, Investigators, Evolocumab and Clinical Outcomes in Patients with Cardiovascular Disease, N Engl J Med 376(18) (2017) 1713-1722.

[224] A co-operative trial in the primary prevention of ischaemic heart disease using clofibrate. Report from the Committee of Principal Investigators, Br Heart J 40(10) (1978) 1069-118.

[225] H. Yokomichi, A. Nagai, M. Hirata, A. Tamakoshi, Y. Kiyohara, Y. Kamatani, K. Muto, T. Ninomiya, K. Matsuda, M. Kubo, Y. Nakamura, G. BioBank Japan Cooperative Hospital, Z. Yamagata, Statin use and all-cause and cancer mortality: BioBank Japan cohort, J Epidemiol 27(3S) (2017) S84-S91.

[226] Y. Morofuji, S. Nakagawa, Drug Development for Central Nervous System Diseases Using In vitro Blood-brain Barrier Models and Drug Repositioning, Curr Pharm Des 26(13) (2020) 1466-1485. 